\title{
Thermophysical Properties of Electric Arc Plasma and the Wire Melting Effect with Lanthanum and Sulfur Fluorides Addition in Wire Arc Additive Manufacturing
}

\author{
Sergey G. Parshin ${ }^{1, *(1)}$ and Peter Mayr ${ }^{2}(\mathbb{D}$ \\ 1 Institute of Mechanical Engineering, Materials and Transport, Peter the Great St. Petersburg Polytechnic \\ University, Polytechnicheskaya 29, 195251 St. Petersburg, Russia \\ 2 Chair of Materials Engineering of Additive Manufacturing, Technical University of Munich, Boltzmann str. \\ 15, 85748 München, Germany; peter.mayr@tum.de \\ * Correspondence: parshin@spbstu.ru; Tel.: +7-812-552-63-55
}

check for

updates

Citation: Parshin, S.G.; Mayr, P. Thermophysical Properties of Electric Arc Plasma and the Wire Melting Effect with Lanthanum and Sulfur Fluorides Addition in Wire Arc Additive Manufacturing. Metals 2021, 11, 1756. https://doi.org/10.3390/ met11111756

Academic Editors: Thomas Niendorf, Mohammed Nouari and Rodolphe Bolot

Received: 19 August 2021

Accepted: 26 October 2021

Published: 1 November 2021

Publisher's Note: MDPI stays neutral with regard to jurisdictional claims in published maps and institutional affiliations.

Copyright: (c) 2021 by the authors. Licensee MDPI, Basel, Switzerland. This article is an open access article distributed under the terms and conditions of the Creative Commons Attribution (CC BY) license (https:// creativecommons.org/licenses/by/ $4.0 /)$.

\begin{abstract}
Achieving a higher quality in wire arc additive manufacturing (WAAM) is a result of the development of welding metallurgy, the development of filler wires, and the control of the thermophysical properties of the electric arc. In this paper, the authors developed composite wires for WAAM with a Ni-LaF, $\mathrm{Ni}-\mathrm{LaB}_{6}$ coating. The addition of $\mathrm{LaF}_{3}, \mathrm{LaB}_{6}$, and $\mathrm{SF}_{6}$ increases specific heat, thermal conductivity, enthalpy, and degree of plasma ionization, which leads to the increase in the transfer of heat from the arc plasma to the wire and to the change in the balance of forces during wire melting. The increase in the Lorentz electromagnetic force and the decrease in the surface tension force made it possible to reduce the droplet diameter and the number of short circuits during wire melting. The change in the thermophysical properties of the plasma and droplet transfer with the addition of $\mathrm{LaF}_{3}, \mathrm{LaB}_{6}$, and $\mathrm{SF}_{6}$ made it possible to increase the welding current, penetration depth, accuracy of the geometric dimensions of products in WAAM, reduce the wall thickness of products, and refine the microstructure of the weld metal using G3Si1, 316L, AlMg5Mn1Ti, and CuCr0.7 wires.
\end{abstract}

Keywords: wire arc additive manufacturing; plasma thermodynamic properties; electric arc; rare earth compounds; wire melting; droplet transfer

\section{Introduction}

Wire arc additive manufacturing (WAAM) is an advanced technology for increasing productivity and reducing costs in the manufacturing of products of steels and alloys [1,2]. WAAM is used to create advanced bionic design products in the car manufacturing, mechanical engineering, and shipbuilding industries including the production of aircraft and rocket engine components. However, the development of WAAM is hindered by the problems with product quality and reliability due to the sensitivity of steels and alloys to the thermal cycle and metallurgical problems of weldability [3]. An analysis of publications related to WAAM reveals that most of the research in this field is conducted in order to improve quality and productivity. There are four advanced areas in this field of study: metallurgy, technology, equipment, and materials (as shown in Figure 1).

The improvement of these areas is associated with advanced research methods, including thermodynamic, mathematical, physical modeling, mechanical engineering and digital data processing, as shown in Figure 1. 


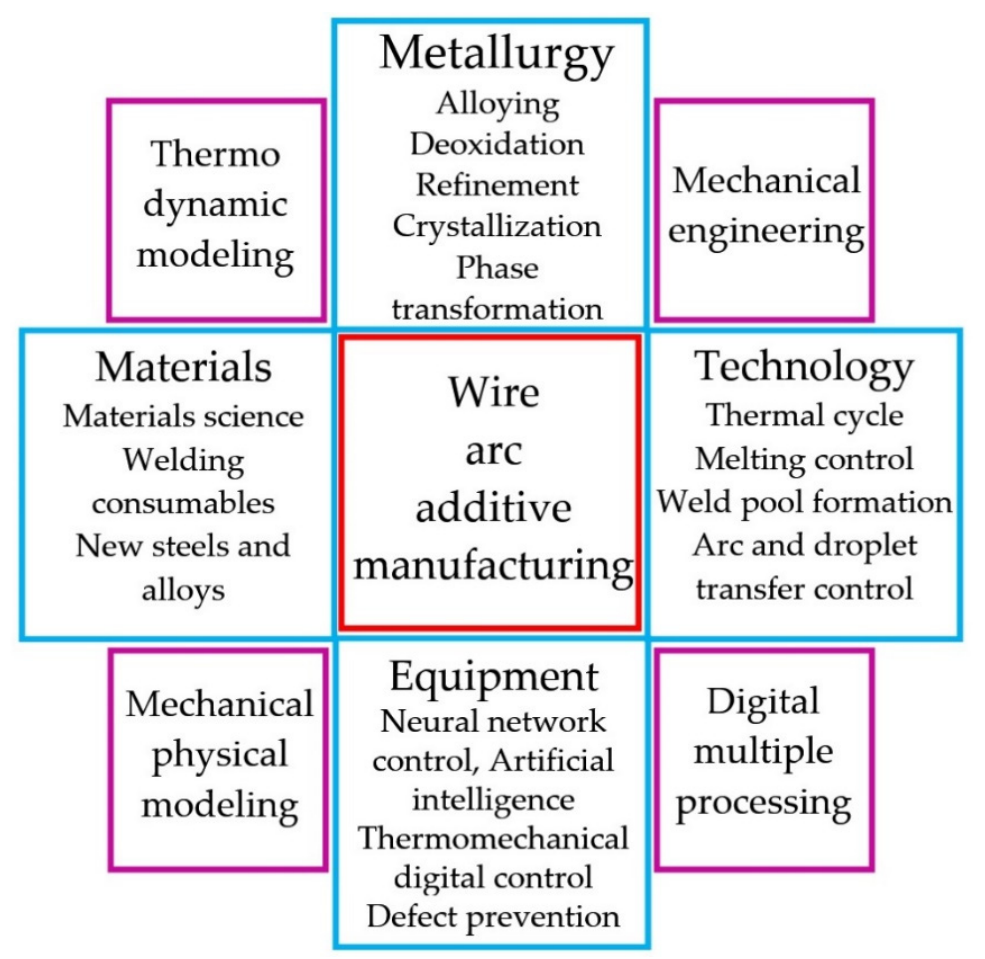

Figure 1. Advanced areas and research methods in the WAAM.

The filler wires and products in WAAM include the following: high-strength, stainless steels [4,5], nickel alloys [6], titanium alloys [7], copper alloys [8,9], aluminum alloys [10-12], magnesium, intermetallic, shape memory alloys, metamaterials, and composites. The application of multicomponent steels and alloys in WAAM leads to typical metallurgical defects: gas porosity, cold, and hot cracks, residual stress and deformation of products, microchemical inhomogeneity, and anisotropy of the macro- and microstructure of the weld metal [13-15]. The occurrence of defects reduces the mechanical properties and reliability of products in dynamic loadings and corrosive environments [16].

The largest number of studies in the field of WAAM are dedicated to the optimization of technologies, improvement of metal melting, optimization of thermal cycle and welding parameters, and improvement of the microstructure and mechanical properties [17-20]. Stützer et al. [17] improved the Gas Metal Arc Welding-Cold Metal Transfer (GMAW-CMT) process and microstructure of duplex steel components in WAAM using the mixing of the electrode and wire. Müller et al. [18] investigated the mechanical properties, microstructure, defects, and local strain maps in specimens using tomography. Ding et al. [19] proposed the FEM models for the prediction and reduction of residual stress in the thermal cycle of WAAM. Dahat et al. [20] proposed a methodology to parametrize WAAM using a high strength low alloy (HSLA) steel for improving the quality and geometry of samples.

The control of the thermal cycle is especially important as it affects wire melting, the formation and geometric dimensions of the products, and the microstructure and properties of the weld metal [21-23]. Lee [21] developed the numerical model for thermal fields and mechanical properties prediction in WAAM using CMT heat source. Rodrigues et al. [22] and Hosseini et al. [23] investigated the mechanical properties and microstructure of HSLA and duplex stainless steel depending on the heat input. The active development of digital current sources, neural network data processing technologies, digital Computer Numerical Control (CNC) machines, and Computer-Aided Design/Computer-Aided Manufacturing (CAD/CAM) systems made it possible to improve the quality of WAAM [24-26].

The development of WAAM is associated with research in the field of welding metallurgy $[27,28]$ and the development of filler wires [29]. Review of Sames et al. [28] confirmed the importance of metallurgical processes in the formation of microstructure defects and residual stresses. The experimental research of Wittig et al. [29] shown significant influence 
of arc energy and filler metal composition on the microstructure of duplex stainless steels. Research in the field of WAAM metallurgy is aimed at improving the microstructure of 718Plus alloy in the process of solidification and the formation of segregations and eutectics [30], improving the properties of the arc plasma [31], and changing the compositions of the shielding gases [32]. Hertel et al. [31] discovered a significant effect of metal vapors on the arc anode spot on the wire melting and droplet transfer at temperatures up to $3300 \mathrm{~K}$. Wagner et al. [32] found the effect of He and Ar shielding gas composition on plasma ionization and the arc radiation.

In our opinion, a comprehensive method is needed to solve WAAM problems. This method is based on controlling the properties of an electric arc, metal melting process, and products formation based on the analysis of physical, thermodynamic, and metallurgical processes.

The physical and metallurgical principle of layer-by-layer formation of a products in WAAM is similar to the process of arc welding of multilayer joints [33]. Sumi et al. [33] solved the problem in narrow gap welding of $100 \mathrm{~mm}$ plate in thickness in $\mathrm{CO}_{2}$ gas shielded arc welding using rare earth metal added wire. Therefore, the control of the properties of the welding arc and the development of special wires is of crucial importance for solving WAAM problems. The electric arc as a thermodynamic system conforms to the principle of temperature self-regulation and thermodynamic equilibrium of H.L. Le Chatelier and the principle of minimum electric field strength of M. Steenbeck. Improvement of arc stability and wire melting is associated with thermophysical characteristics of plasma, plasma ionization, and balance of forces acting during wire melting and formation of a weld pool. Improvement of arc properties can be achieved through modeling an electric arc and controlling thermophysical properties of plasma through the addition of molecular compounds [34,35]. Weglowski [34] determined the presence of ionized iron and manganese vapors in the arc spectrum and suggested using the intensity of the arc radiation for neural network control. Wang et al. [35] calculated the thermophysical properties of plasma at the temperature of 300-100,000 K. Introduction of $\mathrm{H}_{2} \mathrm{O}$ into the plasma increases the specific heat, thermal, and electrical conductivity and decreases the viscosity. To improve the melting of the metal and the formation of the weld pool, it is necessary to study the balance of the forces acting on the plasma flow and the droplet transfer. The addition of rare earth metals and fluorides makes it possible to improve the thermophysical properties of the arc, reduce the spattering in the shielding gas [36], and improve the microstructure and the mechanical properties of the metal product [37]. Kataoka et al. [36] reported the possibility of spray transfer in $\mathrm{CO}_{2}$ using REM added wire. Parshin et al. $[37,38]$ achieved an increase in impact energy of welds in arc welding high-strength steels using composite coated wire with $\mathrm{LaF}_{3}-\mathrm{LaB}_{6}$. Parshin et al. [39-42] investigated the positive effect of $\mathrm{CaF}_{2}$, $\mathrm{AlF}_{3}, \mathrm{KBr}, \mathrm{KF}, \mathrm{NaCl}, \mathrm{BaCl}_{2}, \mathrm{TiO}_{2}$ on increasing the melting coefficient of wires and improving the droplet transfer parameters in the MIG-, MAG-welding of steels and aluminum alloys. Parshin $[43,44]$ found an effect in increasing the stability of the electric arc and the wires melting process when addition of $\mathrm{SF}_{6}$ to argon during MIG welding.

The droplet transfer is determined by the sum forces $F_{S}$ acting on the drop in the wire melting process except the transition process and short circuits [45]:

$$
F_{S}=F_{E M}+F_{D}+F_{G}-F_{S T}-F_{E P},
$$

where $F_{E M}$ is the Lorentz electromagnetic force (pinch effect force); $F_{D}$ is the drag force due to the axial plasma flow past the drop surface; $F_{G}$ is the force of gravity; $F_{S T}$ is the surface tension force; and $F_{E P}$ is the force of the electromagnetic pressure of the arc column.

The electromagnetic force of the pinch effect $F_{E M}$ and the surface tension force $F_{S T}$ make the largest contribution to the sum of the forces $F_{S}$ acting during droplet transfer. The distribution of the Lorentz electromagnetic force $F_{E M}$ in the longitudinal axis of the arc is proportional to the square of the current [46]:

$$
F_{E M}=\frac{\mu}{4 \pi} I^{2} \ln \frac{R}{r_{0}}
$$




$$
F_{E M}=\bar{j} \times \bar{B},
$$

where $\mu$ is magnetic permeability of vacuum; $\mathrm{H} / \mathrm{m} ; \mathrm{I}$ is arc current; $\mathrm{A} ; \mathrm{R}$ is the radius of the arc column, $\mathrm{mm} ; r_{0}$ is the radius of the welding wire, $\mathrm{mm} ; \mathrm{j}$ is the current density, $\mathrm{A} / \mathrm{m}^{2}$; and $B$ is the magnetic induction, $\mathrm{T}$.

The force of surface tension on a drop is determined by the expression [47]:

$$
F_{S T}=2 \pi r \gamma,
$$

where $r$ is the radius of the drop; $\gamma$ is surface tension of liquid metal.

The surface tension of metals and alloys depends on the impurities and decreases with increasing temperature [48]. The surface tension of pure iron decreases with the addition of impurities S, O, N, Ce, P, B [49-51]. The surface tension of iron at $2000 \mathrm{~K}$ with the addition of oxygen from 0.009 to $0.026 \mathrm{wt}$ \% decreases from 1.6 to $1.4 \mathrm{~N} / \mathrm{m}$ [49]. According to Kasama et. al. [50] the surface tension of iron at $1873 \mathrm{~K}$ decreases from 1.8 to $1.2 \mathrm{~N} / \mathrm{m}$ with the addition of oxygen from 0.0025 to $0.1 \mathrm{wt} . \%$. According to Korobeinikov et al. [51] the surface tension of iron at $1823 \mathrm{~K}$ decreases from 1.7 to $1.67 \mathrm{~N} / \mathrm{m}$ with the addition of 0.0062 wt. \% boron.

When the wires are melted in a shielding gas, the anode spot of the arc is located on the surface of the liquid drop. At a high current density in the anode spot of the arc, local evaporation of metal can occur [31]. Local evaporation causes the reactive force $F_{J}$ (jet force) in accordance with Newton's third law of the equality of action and reaction and in accordance with the law of conservation of momentum:

$$
\begin{aligned}
& F_{V}=-F_{J} \\
& F_{V}=\frac{m V}{t},
\end{aligned}
$$

where $F_{V}$ is the force caused by the movement of steam of wt. $m$ with velocity $V$.

The reactive force $F_{J}$ is directed normally to the evaporation surface, and the velocity and wt. of the vapor have a radial distribution similar to the Gaussian distribution of the electromagnetic pressure force $F_{E P}$ [52]. The reactive force $F_{J}$ in the anode affects the droplet transfer, so it should be taken into account when calculating the sum of forces, in our opinion, according to the modified equation:

$$
F_{S}=F_{E M}+F_{D}+F_{G}-F_{S T}-F_{E P}-F_{J} .
$$

In addition to these forces, the droplet transfer is influenced by the tangential force, which arises due to the Marangoni effect. This phenomenon is associated with convective flows of liquid in a molten droplet due to the temperature gradient, the gradient of surface tension and due to the adsorption of surfactants [53]. The Marangoni effect influences the droplet transfer due to the changes in the convection of the liquid metal. Hydrodynamic convection is characterized by fluid velocity and turbulence in accordance with the NavierStokes equation and the Reynolds number [54]. An increase in convection and a decrease in the surface tension of a liquid metal [47] can be achieved by changing the thermophysical properties of the arc plasma and improving heat transfer from the arc plasma to the filler wire [54].

The melting rate of the filler wire (anode) and the droplet diameter depend on the heat $q_{a}$, which is the sum of the heat from the arc plasma $q_{e}$ and the Joule heat $q_{r}$ when the wire is heated due to the electric current flow [55]:

$$
q_{a}=q_{e}+q_{r}=\left(V_{a}+\phi+\frac{3}{2} \frac{k T}{e}\right) I+\frac{L I^{2}}{\pi r^{2} \sigma},
$$


where $\phi$ is the work function of the metal surface; $V_{a}$ is the anode voltage fall; $3 k T / 2 e$ is the thermal energy of electrons; $I$ is the current; $L$ is the wire stickout from the contact tube; $r$ is wire radius; and $\sigma$ is the electrical conductivity of the wire metal.

According to the kinetic theory of gases, the heat of the arc plasma is the sum of the kinetic and potential energies of electrons and heavy particles [56]. Total thermal conductivity $\lambda, \mathrm{W} /(\mathrm{m} \times \mathrm{K})$ of a gas system is determined by the sum of individual thermal conductivities [56]:

$$
\lambda=\lambda_{t r}+\lambda_{\omega}+\lambda_{a m}+\lambda_{d}
$$

where $\lambda_{t r}$ is the sum of thermal conductivities ( $\lambda_{m}$ of molecules, $\lambda_{a}$ of atoms, $\lambda_{i}$ of ions and $\lambda_{e}$ of electrons); $\lambda_{\omega}$ is thermal conductivity during the transfer of excitation energy; $\lambda_{a m}$ is thermal conductivity of ambipolar (ionization) diffusion; and $\lambda_{d}$ is thermal conductivity during diffusion of dissociation energy of molecules.

The transfer of the heat of the arc plasma to the anode (filler wire), heating and melting of the anode depend on the thermal conductivity of the plasma and the material of the anode [57]. The heat flux density $J_{E}\left(\mathrm{~W} / \mathrm{m}^{2}\right)$, the plasma thermal conductivity $\lambda(\mathrm{W} / \mathrm{m} \times \mathrm{K})$, and the heat capacity $c_{V}$ are described by the relations [58]:

$$
\begin{gathered}
J_{E}=-\lambda \nabla T \\
\lambda=\eta c_{V}=D \rho c_{V},
\end{gathered}
$$

where $D$ is coefficient of diffusion (self-diffusion) of gas, $\mathrm{m}^{2} / \mathrm{s} ; c_{V}$ is specific heat capacity at constant volume, $\mathrm{J} /(\mathrm{kg} \times \mathrm{K}) ; \eta$ is dynamic viscosity, $\mathrm{kg} /(\mathrm{m} \times \mathrm{s})$; and $\rho$ is density, $\mathrm{kg} / \mathrm{m}^{3}$.

According to the Kirchhoff equation, the change in the heat capacity of the system $\Delta c_{P}$ at constant pressure $p$ is determined by the dependence of enthalpy $\Delta H$ on the temperature $T$ :

$$
\Delta c_{P}=\left(\frac{d \Delta H}{d T}\right)_{P} .
$$

The equilibrium constant of the reaction $K_{R}$, the change in the Gibbs energy $\Delta G$, and the change in enthalpy $\Delta H$ are described by the Gibbs relations:

$$
\begin{aligned}
& -R T \ln K_{R}=\Delta G \\
& \Delta G=\Delta H-T \Delta S .
\end{aligned}
$$

The equilibrium constants of dissociation and ionization reactions of a substances is determined by the dependence of enthalpy $\Delta H$ on the temperature $T$ according to the Van't Hoff equation:

$$
\left(\frac{\partial \ln K_{R}}{\partial \mathrm{T}}\right)_{v}=\frac{\Delta H}{R T^{2}} .
$$

Thus, endothermic dissociation and ionization reactions can increase the heat capacity, enthalpy, and thermal conductivity of plasma. This effect facilitates the transfer of the amount of heat from the arc plasma to the surface of the wire-anode and the weld pool. An increase in the thermal conductivity of the plasma and the amount of heat on the wire-anode can increase the temperature of the droplets, decrease the surface tension, and enhance the convection of the liquid metal. Adsorption of La, S, and B on the surface of a liquid droplet can further reduce the surface tension and increase the sum of the forces $F_{S}$, facilitating the droplet transfer. When modeling, it is necessary to take into account that the content of metal vapors in the arc plasma amounts to $10 \%$, which can significantly change its thermophysical properties [59].

We assume that the changes in the thermophysical properties of the plasma and the balance of forces should improve the droplet transfer and decrease the droplet diameter during melting of the filler wire. The metallurgical effect of lanthanum fluoride $\mathrm{LaF}_{3}$, lanthanum boride $\mathrm{LaB}_{6}$, and gaseous sulfur hexafluoride $\mathrm{SF}_{6}$ in WAAM has not been previously studied, which determines the scientific novelty and relevance of this study. 
The aim of the study is to change the thermophysical properties of an electric arc plasma, droplet transfer and products formation in WAAM by introducing lanthanum fluoride $\mathrm{LaF}_{3}$, lanthanum boride $\mathrm{LaB}_{6}$, sulfur hexafluoride $\mathrm{SF}_{6}$ into argon using wires of G3Si1, 316L, AlMg5Mn, CuCr0.7.

\section{Materials and Methods}

For research, we used G3Si1 wire of $1.2 \mathrm{~mm}$ in diameter according to EN ISO 14341: 2020, 316L wire of $1 \mathrm{~mm}$ in diameter according to EN ISO 14343:2017, AlMg5Mn1Ti wire of $1.6 \mathrm{~mm}$ in diameter according to EN ISO 18273:2015 (ESAB, Gothenburg, Kingdom of Sweden), CuCr0.7 bronze wire (Plant of Quality Alloys, Moscow, Russia) according to EN ISO 24373:2018 (according to GOST 16130-90 in Russian) of $1.6 \mathrm{~mm}$ in diameter with a chemical composition as shown in Table 1.

Table 1. Chemical composition of filler wires, wt.\%.

\begin{tabular}{|c|c|c|c|c|c|c|c|c|c|}
\hline Wire & $\mathrm{C}$ & Mn & Si & Mo & $\mathrm{Cr}$ & $\mathrm{Ni}$ & $S$ & $\mathbf{P}$ & Others \\
\hline $\begin{array}{c}\text { G3Si1 } 1.2 \\
\text { mm }\end{array}$ & $0.06-0.14$ & $1.4-1.6$ & $0.8-1$ & - & - & - & $<0.025$ & $<0.025$ & $<97.2 \mathrm{Fe}$ \\
\hline $\begin{array}{l}\text { 316L } 1.0 \\
\text { mm }\end{array}$ & $<0.03$ & $<2$ & $<0.075$ & $2-3$ & $16-18$ & $10-14$ & $<0.03$ & $<0.045$ & $<64.82 \mathrm{Fe}$ \\
\hline $\begin{array}{l}\text { AlMg5Mn1Ti } \\
1.6 \mathrm{~mm}\end{array}$ & - & $0.5-1$ & $<0.25$ & - & $0.05-0.2$ & - & - & - & $<98.55 \mathrm{Al}$ \\
\hline $\begin{array}{c}\text { CuCr0.7 } \\
1.6 \mathrm{~mm}\end{array}$ & - & - & - & - & $0.4-1$ & $<0.01$ & $<0.01$ & $<0.005$ & $<98.9 \mathrm{Cu}$ \\
\hline
\end{tabular}

Standard wires G3Si1, 316L of 1; $1.2 \mathrm{~mm}$ in diameter were treated according to electrochemical technology in an electrolyte with the composition: $500 \mathrm{~g} / \mathrm{L} \mathrm{Ni}\left(\mathrm{BF}_{4}\right)_{2}$, $50 \mathrm{~g} / \mathrm{L} \mathrm{LaF}_{3}$ or $\mathrm{LaB}_{6}$, the solvent is ethanol $\mathrm{C}_{2} \mathrm{H}_{6} \mathrm{O}$ [37]. The principle of the process is shown in Figure 2.

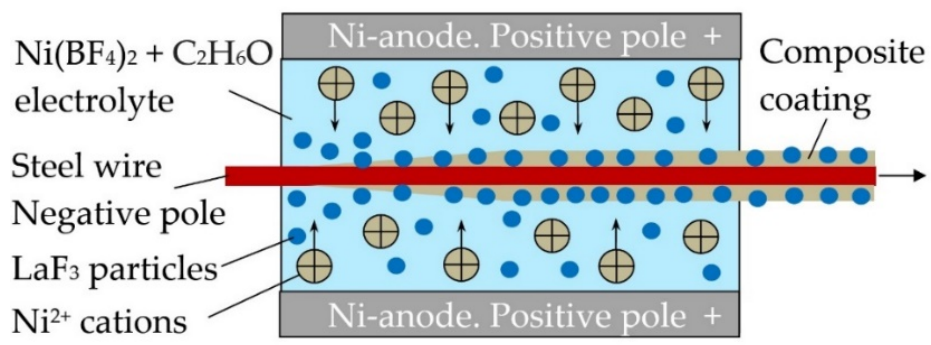

Figure 2. The principle of electrochemical formation of a composite coating on the surface of the wire.

After processing, a composite coating with a thickness of about $5 \mu \mathrm{m}$ was formed on the surface of the wires from a nickel matrix and nanodispersed particles of $\mathrm{LaF}_{3}$ or lanthanum boride $\mathrm{LaB}_{6}$ with $0.3-0.7 \mu \mathrm{m}$ particle diameter, as shown in Figure 3. 


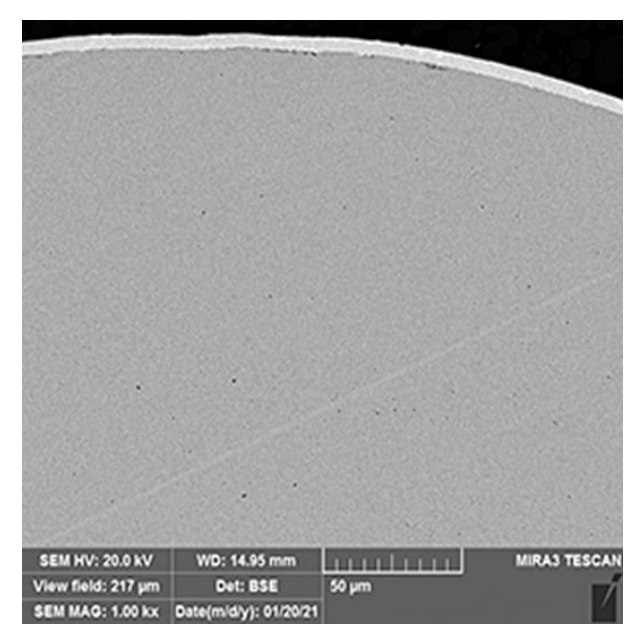

Figure 3. SEM image of the microstructure of composite $\mathrm{Ni}^{-\mathrm{LaF}_{3}}$ coatings on the surface of the wire.

Sulfur hexafluoride $\mathrm{SF}_{6}: \mathrm{SF}_{6}>99.9 \%, \mathrm{H}_{2} \mathrm{O}<5$ ppm, $\mathrm{CF}_{4}<500$ ppm, air $<500$ ppm (Linde AG, Pullach, Germany) was introduced into pure argon through a WITT KM gas mixer 80-3 (WITT-Gasetechnik GmbH, Witten, Germany) in the ratio, \%: 1.6; 3.2; 4.8; 6.4. $\mathrm{SF}_{6}$ concentrations were calculated taking into account the volume and molar mass.

Investigations of the droplet transfer were carried out by the shadow method using a laser system when weld deposition on a rotating pipe. Video recording was made with a high-speed video camera Phantom V310 (Vision Research Inc., Wayne, NJ, USA) at 2000 fps. Phantom CV software (Vision Research Inc., Wayne, NJ, USA) was used for image visualization and analysis. The source was Lorch-Schweißanlage S-RoboMIG XT (Lorch Schweißtechnik GmbH Auenwald, Germany). Arc voltage and current were determined using a digital USB-oscillograph and DIAdem-2020 program (National Instruments, Austin, TX, USA). Welding parameters for wire melting are given in Table 2.

Table 2. Welding parameters in the study of wire melting.

\begin{tabular}{cccc}
\hline Wire & Current, A & Voltage, $\mathbf{~}$ & Wire Feed Rate, m/min \\
\hline G3Si1 1.2 mm & 221 & 19 & 5 \\
316L 1.0 mm & 215 & 13 & 5 \\
AlMg5Mn1Ti 1.6 mm & 140 & 20 & 6 \\
\hline
\end{tabular}

To study the process, robotic layer-by-layer weld deposition of specimens $35-50 \mathrm{~mm}$ in height and $150 \mathrm{~mm}$ in length was performed. For arc weld deposition in argon, a Comau Smart NC-16-1.65 robot (Comau, Turin, Italy) with a Fronius TransPuls Synergic 4000 CMT/RCU 5000i source (Fronius International GmbH, Pettenbach, Austria) was used, in accordance with the welding parameters specified in Table 3.

Table 3. Welding parameters for the multilayer CMT-standard weld deposition.

\begin{tabular}{ccccc}
\hline Wire & Current, A & Voltage, $\mathbf{~}$ & $\begin{array}{c}\text { Wire Feed Rate, } \\
\mathbf{m} / \mathbf{m i n}\end{array}$ & Travel Speed, m/min \\
\hline G3Si1 1.2 mm & 98 & 14.6 & 2.1 & 0.6 \\
316L 1.0 mm & 64 & 12.9 & 2.3 & 0.4 \\
AlMg5Mn1Ti 1.6 mm & 110 & 15 & 3.0 & 0.8 \\
CuCr0.7 1.6 mm & 130 & 14.5 & 3.2 & 0.8 \\
\hline
\end{tabular}

For thermodynamic modeling of the plasma thermophysical properties and the phase composition of plasma, were used the program IVTANTHERMO (Joint Institute for High Temperatures of the Russian Academy of Sciences, Moscow, Russia). 


\section{Results}

When fluoride $\mathrm{LaF}_{3}$ and boride $\mathrm{LaB}_{6}$ are added into the plasma of an electric arc, evaporation, dissociation, and ionization occur according to the endothermic reactions (16)-(20):

$$
\begin{gathered}
\mathrm{LaF}_{3}=\mathrm{La}+3 \mathrm{~F} \\
\mathrm{LaB}_{6}=\mathrm{La}+6 \mathrm{~B} \\
\mathrm{Ar}=\mathrm{Ar}^{+}+\mathrm{e} \\
\mathrm{La}=\mathrm{La}^{+}+\mathrm{e} \\
\mathrm{B}=\mathrm{B}^{+}+\mathrm{e}
\end{gathered}
$$

As a result of dissociation and ionization reactions, the arc plasma consists of a complex mixture of molecules, atoms and ions, as shown in Figure 4.

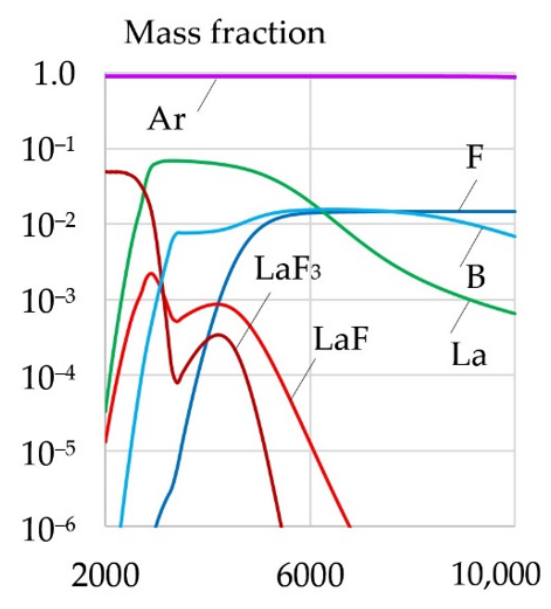

Temperature, $\mathrm{K}$

(a)

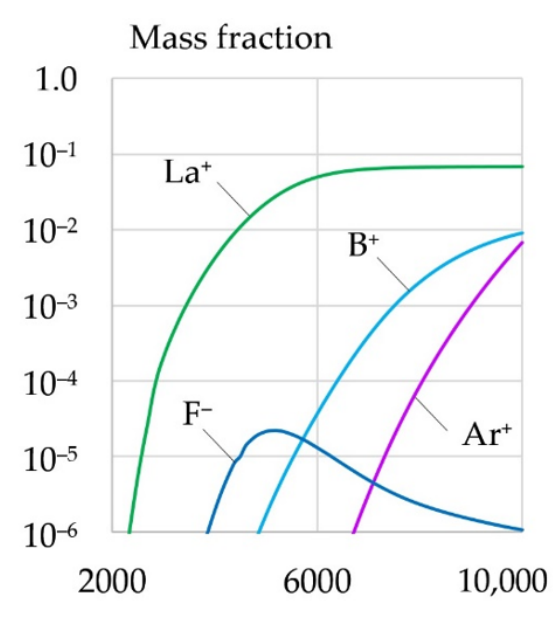

Temperature, $\mathrm{K}$

(b)

Figure 4. Mass fraction of components during dissociation (a) and ionization (b) of the mixture, wt.\%: $90 \mathrm{Ar}+5 \mathrm{LaF}_{3}+5 \mathrm{LaB}_{6}$.

At the boundary of the arc plasma at $4000-5000 \mathrm{~K}$, negative ions $\mathrm{F}^{-}$are formed. The formation of positive $\mathrm{La}^{+}$ions with ionization energy of $5.57 \mathrm{eV}$ and boron $\mathrm{B}^{+}$with ionization energy of $8.29 \mathrm{eV}$ increases the degree of ionization of the arc plasma.

Dissociation of $\mathrm{SF}_{6}$ fluoride at $1000-6000 \mathrm{~K}$ occurs with the formation of compounds $\mathrm{SF}_{4}, \mathrm{SF}_{2}, \mathrm{SF}, \mathrm{F}$, and with the formation of negative ions $\mathrm{F}^{-}$and $\mathrm{S}^{-}$. According to thermodynamic modeling, with $\mathrm{SF}_{6}$, the degree of plasma ionization at the center of the arc is higher compared to the addition of $\mathrm{LaF}_{3}$ and $\mathrm{LaB}_{6}$ due to the ionization of $\mathrm{Ar}^{+}$atoms, as shown in Figure 5. 


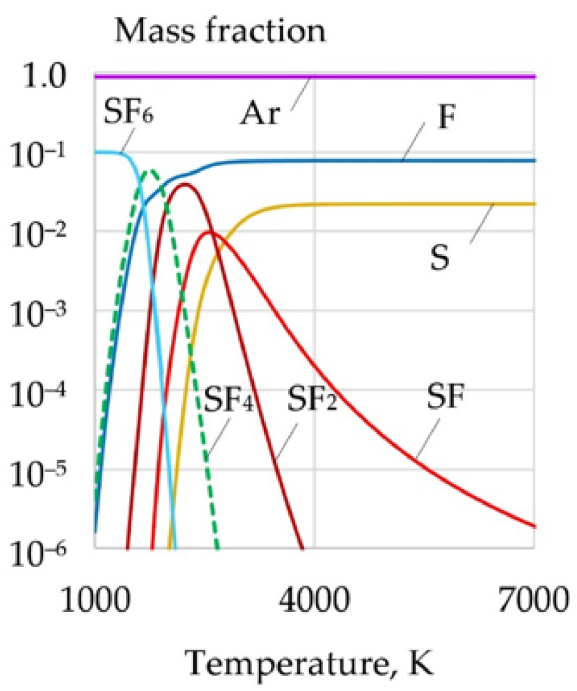

(a)

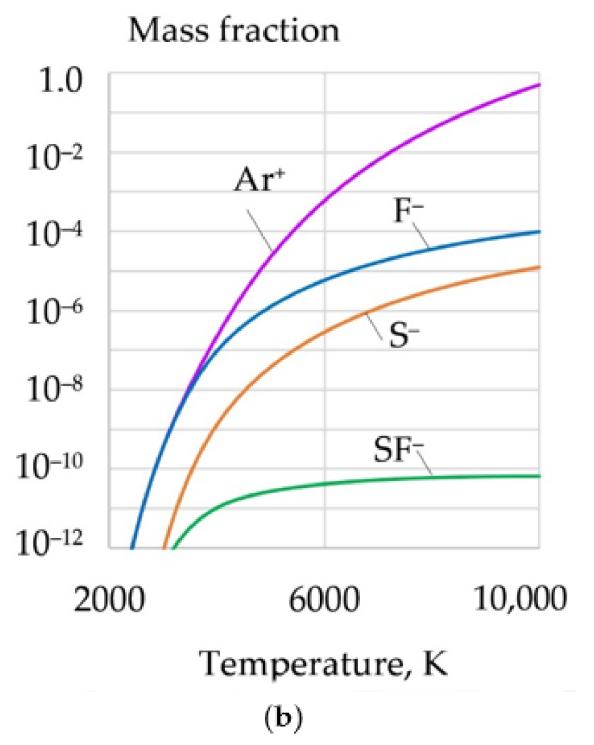

Figure 5. Mass fraction of components during dissociation (a) and ionization (b) of the mixture, wt.\%: $90 \mathrm{Ar}+10 \mathrm{SF}_{6}$.

Endothermic reactions of dissociation and ionization of $\mathrm{LaF}_{3}$ with a positive change in enthalpy lead to an increase in heat capacity, thermal conductivity, enthalpy of the plasma, and slight decrease in dynamic viscosity, as shown in Figure 6.

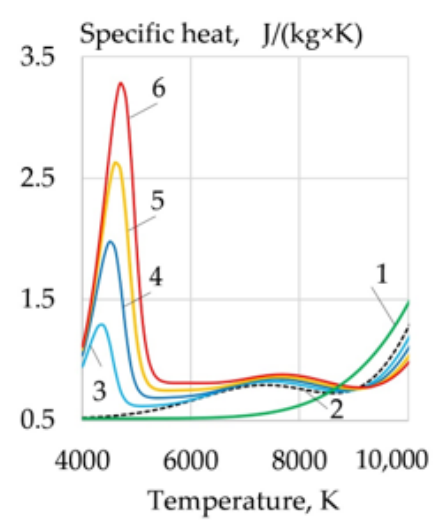

(a)

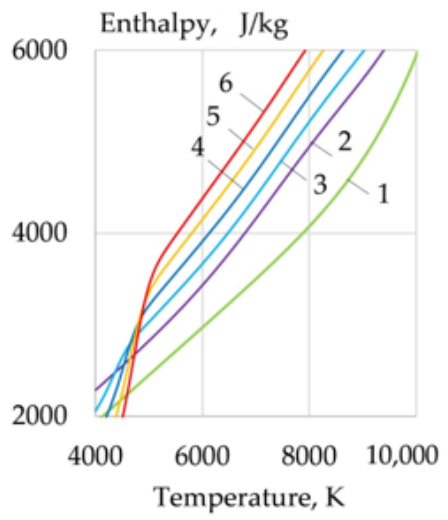

(c)

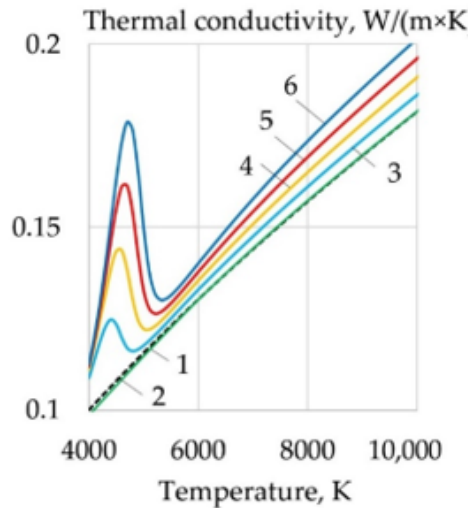

(b)

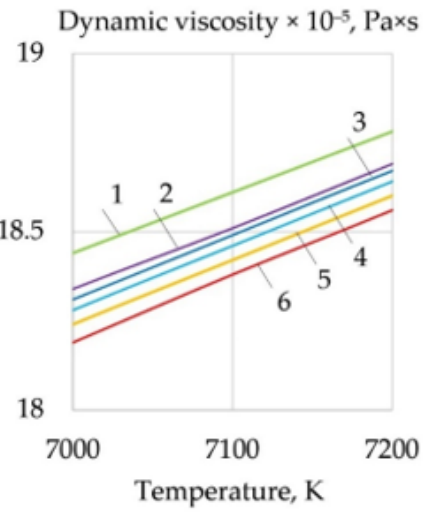

(d)

Figure 6. Change in specific heat (a), thermal conductivity (b), enthalpy (c), and dynamic viscosity (d) of an equilibrium system at $0.1 \mathrm{MPa}$, wt.\%: (1) $100 \mathrm{Ar}$; (2) $95 \mathrm{Ar}+5 \mathrm{Fe}$ : (3) $90 \mathrm{Ar}+5 \mathrm{Fe}+5 \mathrm{LaF}_{3}$; (4) $85 \mathrm{Ar}+5 \mathrm{Fe}+10 \mathrm{LaF}_{3} ;(5) 80 \mathrm{Ar}+5 \mathrm{Fe}+15 \mathrm{LaF}_{3} ;(6) 75 \mathrm{Ar}+5 \mathrm{Fe}+20 \mathrm{LaF}_{3}$. 
When $\mathrm{LaF}_{3}$ is added, a significant increase in the specific heat and thermal conductivity of the plasma occurs at the arc boundary at temperatures of 4000-5000 K, in the zone of molecular dissociation reactions. The addition of $\mathrm{LaB}_{6}$ increases the specific heat, thermal conductivity and enthalpy of plasma at temperatures of $6000-10,000 \mathrm{~K}$ and reduces the dynamic viscosity of the plasma, as shown in Figure 7.

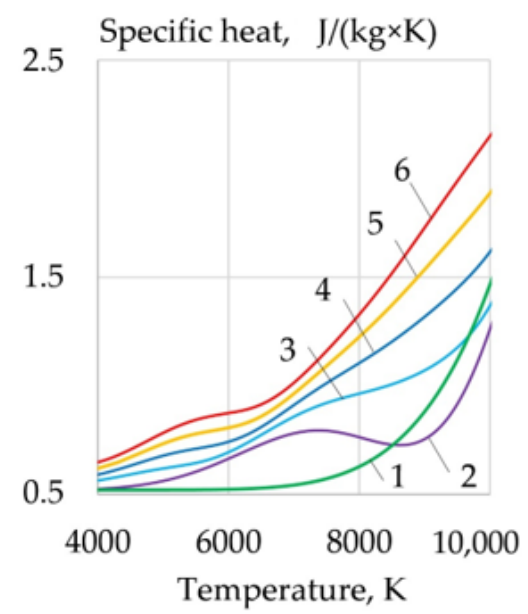

(a)

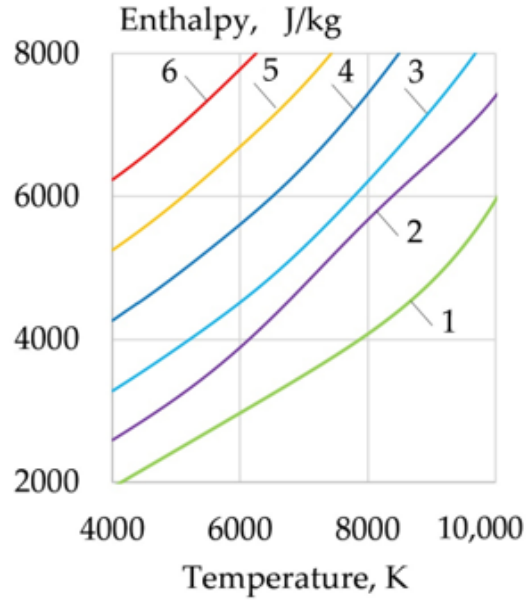

(c)

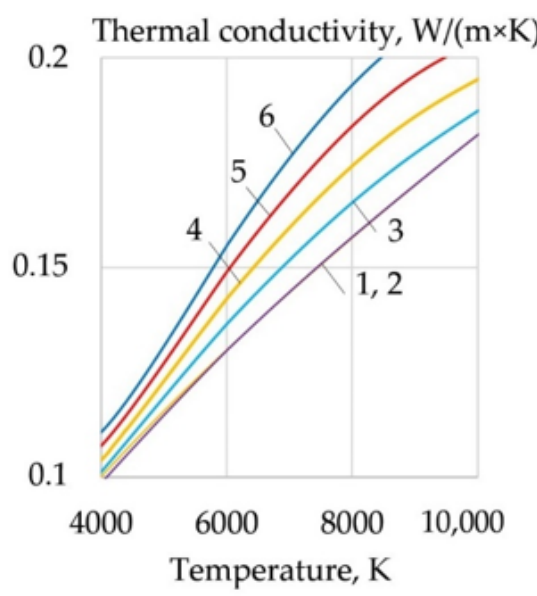

(b)

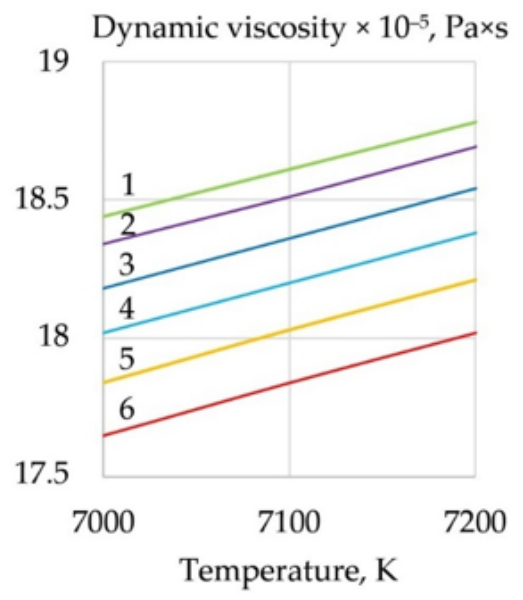

(d)

Figure 7. Change in specific heat (a), thermal conductivity (b), enthalpy (c), and dynamic viscosity (d) of an equilibrium system at $0.1 \mathrm{MPa}$, wt.\%: (1) $100 \mathrm{Ar}$; (2) $95 \mathrm{Ar}+5 \mathrm{Fe}$; (3) $90 \mathrm{Ar}+5 \mathrm{Fe}+5 \mathrm{LaB}_{6}$; (4) $85 \mathrm{Ar}+5 \mathrm{Fe}+10 \mathrm{LaB}_{6} ;(5) 80 \mathrm{Ar}+\mathrm{Fe}+15 \mathrm{LaB}_{6} ;(6) 75 \mathrm{Ar}+5 \mathrm{Fe}+20 \mathrm{LaB}_{6}$.

The addition of $\mathrm{SF}_{6}$ causes a significant increase in thermal conductivity at the arc boundary at $4000-6000 \mathrm{~K}$ due to intense dissociation reactions, and also increases the specific heat, enthalpy, and decreases the dynamic viscosity of the plasma, as shown in Figure 8. 


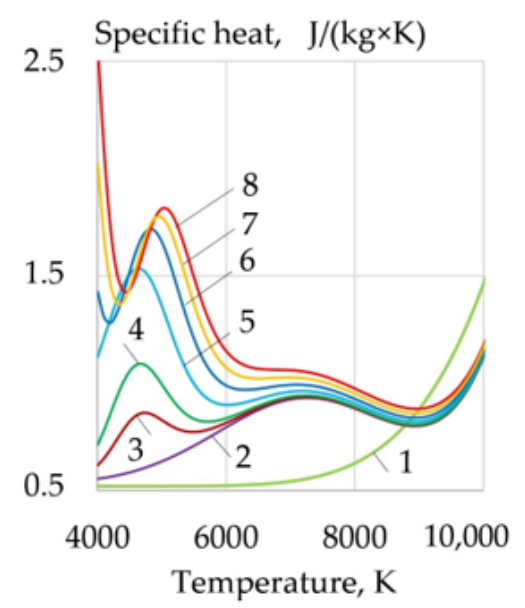

(a)

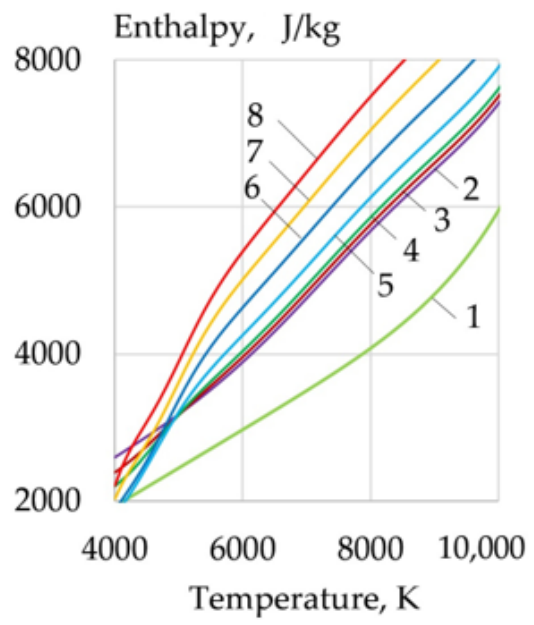

(c)

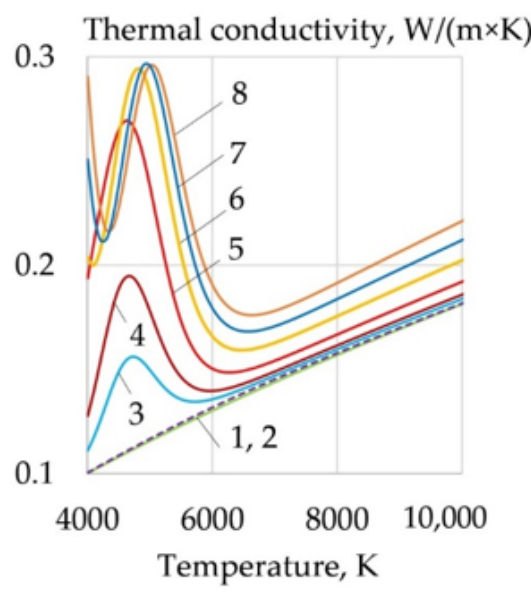

(b)

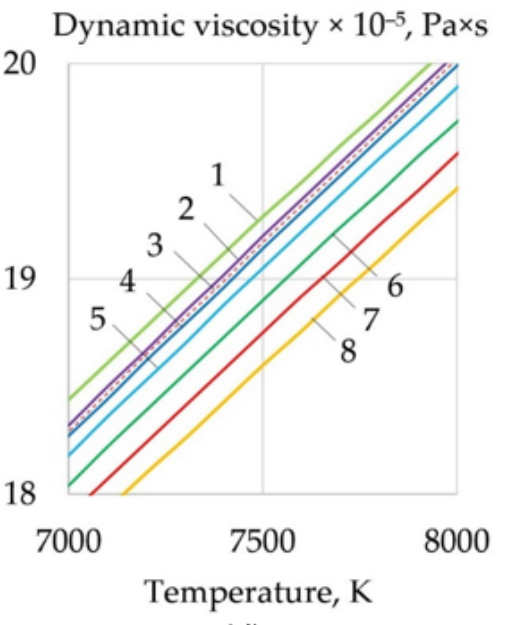

(d)

Figure 8. Change in specific heat (a), thermal conductivity (b), enthalpy (c), and dynamic viscosity (d) of an equilibrium system at $0.1 \mathrm{MPa}$, wt.\%: (1) $100 \mathrm{Ar}$; (2) $95 \mathrm{Ar}+5 \mathrm{Al}$; (3) $94 \mathrm{Ar}+5 \mathrm{Al}+1 \mathrm{SF}_{6}$; (4) $93 \mathrm{Ar}+5 \mathrm{Al}+2 \mathrm{SF}_{6} ;(5) 90 \mathrm{Ar}+5 \mathrm{Al}+5 \mathrm{SF}_{6} ;(6) 85 \mathrm{Ar}+5 \mathrm{Al}+10 \mathrm{SF}_{6} ;(7) 80 \mathrm{Ar}+5 \mathrm{Al}+15 \mathrm{SF}_{6} ;(8) 75 \mathrm{Ar}$ $+5 \mathrm{Al}+20 \mathrm{SF}_{6}$.

The addition of $\mathrm{LaF}_{3}, \mathrm{LaB}_{6}$, and $\mathrm{SF}_{6}$ into the plasma leads to the formation of positive ions $\mathrm{La}^{+}$, boron $\mathrm{B}^{+}$, and the formation of negative ions $\mathrm{F}^{-}, \mathrm{S}^{-}$. An increase in the ion concentration leads to an uneven distribution of charged particles in the longitudinal and transverse directions, to an increase in the degree of plasma ionization and to an increase in the concentration of electrons, as shown in Figure 9. 


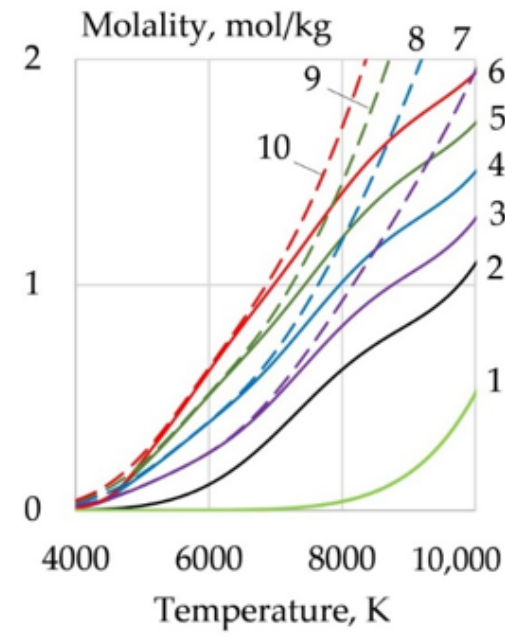

(a)

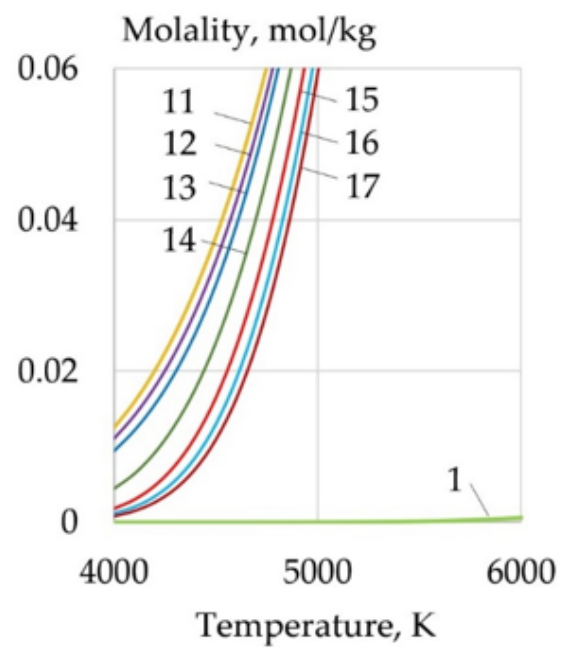

(b)

Figure 9. Change in the concentration of electrons in the equilibrium system, wt.\% at $0.1 \mathrm{MPa}$ : $95 \mathrm{Ar}$ + 5Fe (a) and 95Ar + 5Al (b) at $0.1 \mathrm{MPa}$ (1) $100 \mathrm{Ar} ;(2) 95 \mathrm{Ar}+5 \mathrm{Fe} ;(3) 90 \mathrm{Ar}+5 \mathrm{Fe}+5 \mathrm{LaF}_{3} ;(4) 85 \mathrm{Ar}+$ $5 \mathrm{Fe}+10 \mathrm{LaF}_{3} ;(5) 80 \mathrm{Ar}+5 \mathrm{Fe}+15 \mathrm{LaF}_{3} ;(6) 75 \mathrm{Ar}+5 \mathrm{Fe}+20 \mathrm{LaF}_{3} ;(7) 90 \mathrm{Ar}+5 \mathrm{Fe}+5 \mathrm{LaB}_{6} ;(8) 85 \mathrm{Ar}+$ $5 \mathrm{Fe}+10 \mathrm{LaB}_{6} ;(9) 80 \mathrm{Ar}+5 \mathrm{Fe}+15 \mathrm{LaB}_{6} ;(10) 75 \mathrm{Ar}+5 \mathrm{Fe}+20 \mathrm{LaB}_{6} ;(11) 95 \mathrm{Ar}+5 \mathrm{Al} ;(12) 94 \mathrm{Ar}+5 \mathrm{Al}+$ $1 \mathrm{SF}_{6} ;(13) 93 \mathrm{Ar}+5 \mathrm{Al}+2 \mathrm{SF}_{6} ;(14) 90 \mathrm{Ar}+5 \mathrm{Al}+5 \mathrm{SF}_{6} ;(15) 85 \mathrm{Ar}+5 \mathrm{Al}+10 \mathrm{SF}_{6} ;(16) 80 \mathrm{Ar}+5 \mathrm{Al}+15 \mathrm{SF}_{6}$; (17) $75 \mathrm{Ar}+5 \mathrm{Al}+20 \mathrm{SF}_{6}$.

The addition of $\mathrm{SF}_{6}$ leads to a decrease in the electron concentration from 0.06 to $0.02 \mathrm{~mol} / \mathrm{kg}$ at the arc boundary at $4000-5000 \mathrm{~K}$, which is explained by intense deionization and the formation of negative $\mathrm{F}^{-}$and $\mathrm{S}^{-}$ions. However, the addition of $\mathrm{SF}_{6}$ together with $5 \% \mathrm{Al}$ vapor leads to an increase in the electron concentration in the center of the arc from 0.5 to $1.9 \mathrm{~mol} / \mathrm{kg}$ at $10,000 \mathrm{~K}$.

Thus, the dissociation of fluorides $\mathrm{LaF}_{3}, \mathrm{SF}_{6}$, and boride $\mathrm{LaB}_{6}$ results in an increase in specific heat, thermal conductivity, enthalpy of plasma from a mixture of argon, and $5 \%$ metal vapor. The degree of influence of the components on the properties of the plasma depends on the composition, concentration of particles, and temperature. The improvement in heat transfer occurs both at the boundary of the arc and at the center of the arc, depending on the composition of the components. The change in thermophysical properties is explained by the dissociation of molecular impurities $\mathrm{LaF}_{3}, \mathrm{SF}_{6}, \mathrm{LaB}_{6}$, and an increase in the concentration of electrons, the energy of which makes the greatest contribution to the total thermal conductivity of the plasma. An increase in the electron concentration, as we predict, should lead to an increase in the anode voltage fall (which requires further study).

A slight decrease in dynamic viscosity can be explained by a decrease in the mean free path of particles and a decrease in the diffusion coefficient of particles due to an increase in the density of an ionized multicomponent plasma. The results are consistent with those of Murphy et al. [60] on the effect of addition of molecular gases on the thermophysical properties of argon. According to research by Murphy et al., the addition of molecular impurities into argon in the presence of iron vapor increases the thermal conductivity, specific heat, and enthalpy of the system and decreases the dynamic viscosity of the plasma at dissociation temperatures of molecular impurities of 2500-5000 K.

To confirm our hypothesis about the improvement of the droplet transfer due to the changes in the thermophysical properties of the plasma, the melting of the welding wires was studied. Melting of the G3Si1 wire with $1.2 \mathrm{~mm}$ in diameter in argon occurred with the formation of large droplets up to $2.5 \mathrm{~mm}$ in diameter, as shown in Figure 10a. 


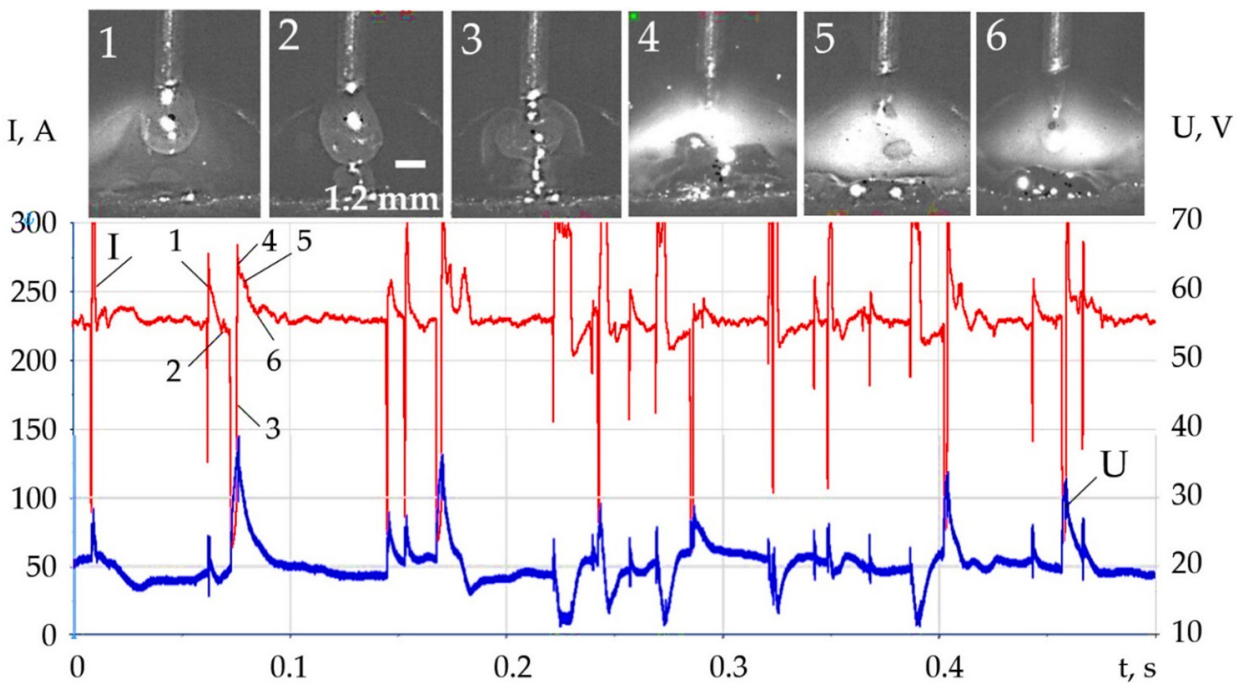

(a)

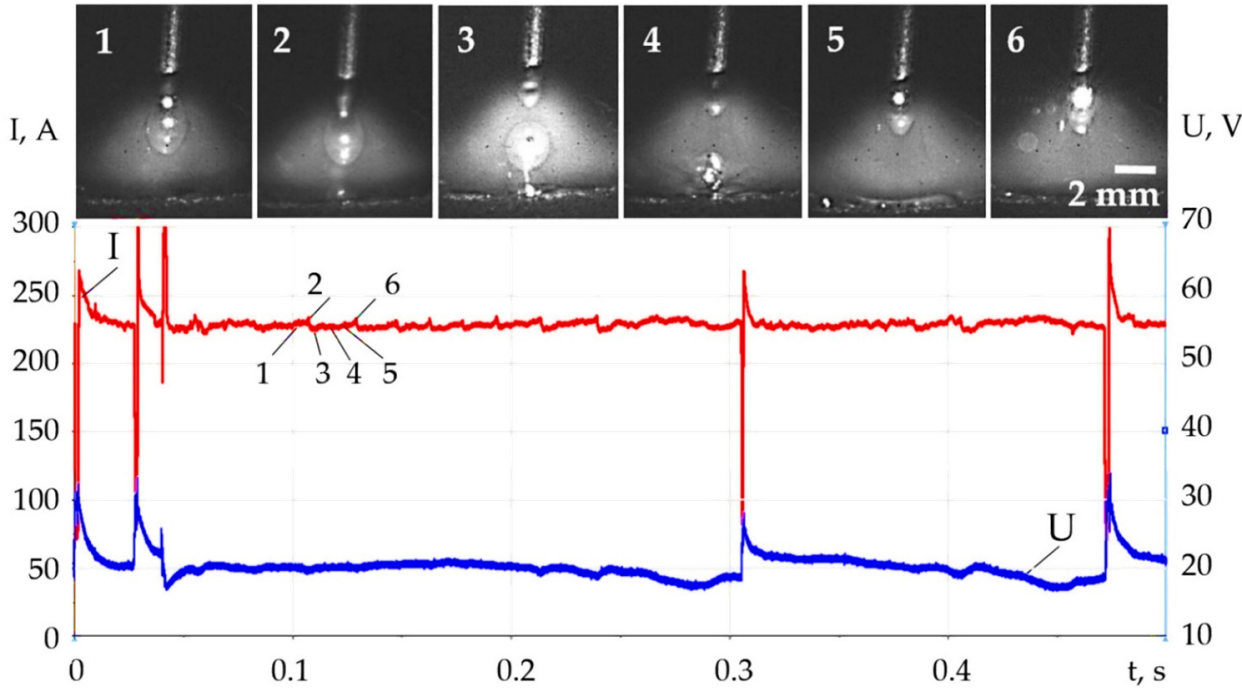

(b)

Figure 10. Change in current and sequence of droplet transfer during melting of G3Si1 wire of $1.2 \mathrm{~mm}$ in argon: (a) uncoated wire; (b) wire with $\mathrm{Ni}-\mathrm{LaF}_{3}$ coating of $5 \mu \mathrm{m}$; time between the frames is $5 \mathrm{~ms} ; 1-6$ is a sequence of frames.

The transfer of droplets occurred with short circuits at a frequency of 35-40 Hz. When the droplet was touched on the weld pool surface, the phenomenon of a short-term current interruption was observed for 1-2 ms. The reason of current interruption was probably due to the presence of an electrically insulating oxide film on the surface of the weld pool or the presence of a vapor phase with low electrical conductivity and thermal conductivity. The average arc length was $6 \mathrm{~mm}$ at welding current of 205-238 A, an arc voltage of 16-22 V, a power of 3.3-5.2 kW. When analyzing the average welding parameters, sharp fluctuations in transient processes during short circuits and arc breaks were not taken into account.

The melting study of G3Si1 wire with $5 \mu \mathrm{m}$ thickness $\mathrm{Ni}-\mathrm{LaF}_{3}$ coating showed a decrease in the droplet diameter to $2 \mathrm{~mm}$ and the frequency of short circuits to $2-4 \mathrm{~Hz}$, as shown in Figure 10b. The duration of the short-term interruption of the current when the droplet closes on the weld pool decreased to $0.1-0.16 \mathrm{~ms}$. The average arc length was reduced to $4.8 \mathrm{~mm}$ at a current of 221-238 A, an arc voltage of 17-22 $\mathrm{V}$, a power of 3.7-5.2 kW. With an increase in the thickness of the Ni-LaF 3 coating on the G3Si1 wire to 
$15 \mu \mathrm{m}$, a drop-streaming metal transfer mode occurred with a droplet diameter of $0.5-1 \mathrm{~mm}$ and a stream diameter of up to $0.3 \mathrm{~mm}$ without short circuits, as shown in Figure 11.

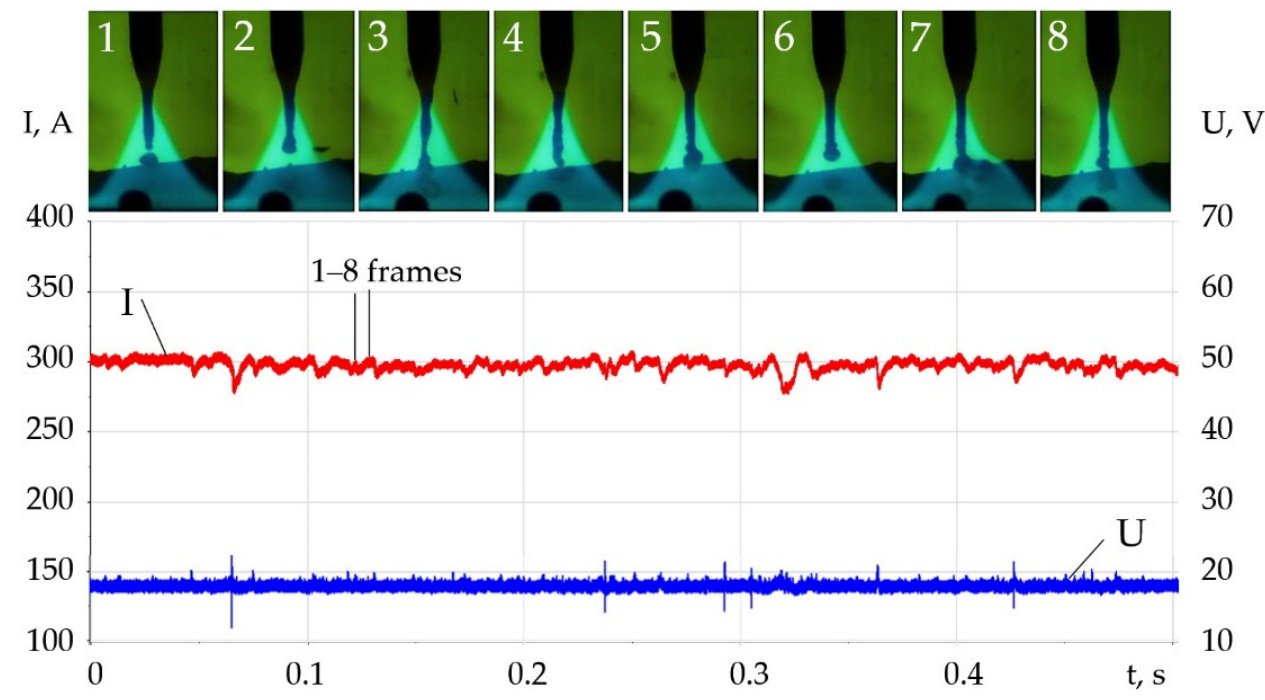

Figure 11. Change in the current and metal spray transfer during melting of a G3Si1 wire of $1.2 \mathrm{~mm}$ in argon with a Ni-LaF 3 coating of $15 \mu \mathrm{m}$; time between the frames is $0.5 \mathrm{~ms} ; 1-8$ is a sequence of frames.

The average arc length was reduced to $2 \mathrm{~mm}$ at a welding current of 277-309 A. Thus, using a composite coating significantly improved the droplet transfer characteristics and the stability of the welding arc. Welding current increased by $7 \%$, arc voltage by $6 \%$, power by $12 \%$. The application of $15 \mu \mathrm{m}$ thickness coating led to an increase in current by $29-35 \%$. When weld deposition with G3Si1 wire, the weld width at a wire feed rate of 7-10 m/min decreased in argon by $18-25 \%$, and the depth of penetration increased by $20-38 \%$.

Melting of 316L wire with $1.0 \mathrm{~mm}$ in diameter in argon occurred with the formation of large droplets up to $2.6 \mathrm{~mm}$ in diameter, with a short circuit frequency of $10-12 \mathrm{~Hz}$, as shown in Figure 12a.

The average arc length was $6 \mathrm{~mm}$, welding current of 202-228 A, arc voltage of 12-13 V, power of $2.6-3 \mathrm{~kW}$. The study of $316 \mathrm{~L}$ wire with a $5 \mu \mathrm{m}$ thickness $\mathrm{Ni}^{-\mathrm{LaB}_{6}}$ coating showed a decrease in the droplet diameter to 1.2-2 mm during melting, as shown in Figure 12b. The average arc length was $4.4 \mathrm{~mm}$ at the welding current of 208-250 A, the arc voltage of $12.2-13.2 \mathrm{~V}$, and the power of $2.6-3.4 \mathrm{~kW}$. 


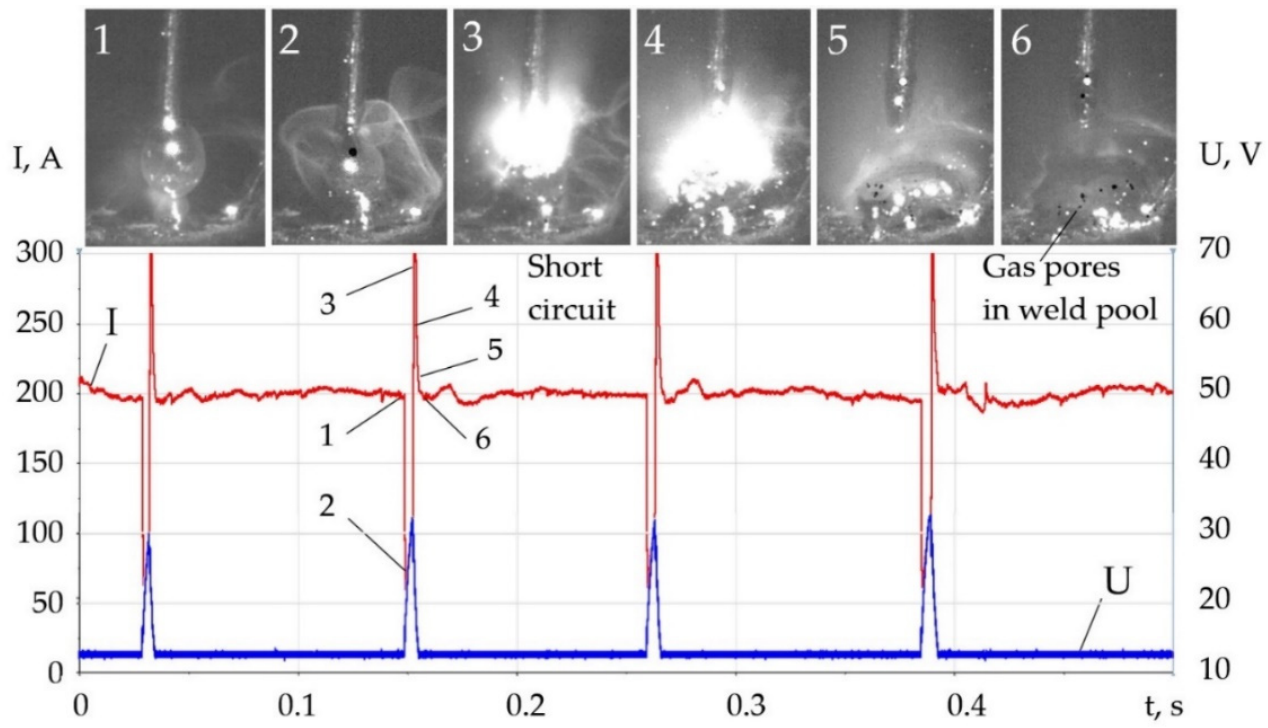

(a)

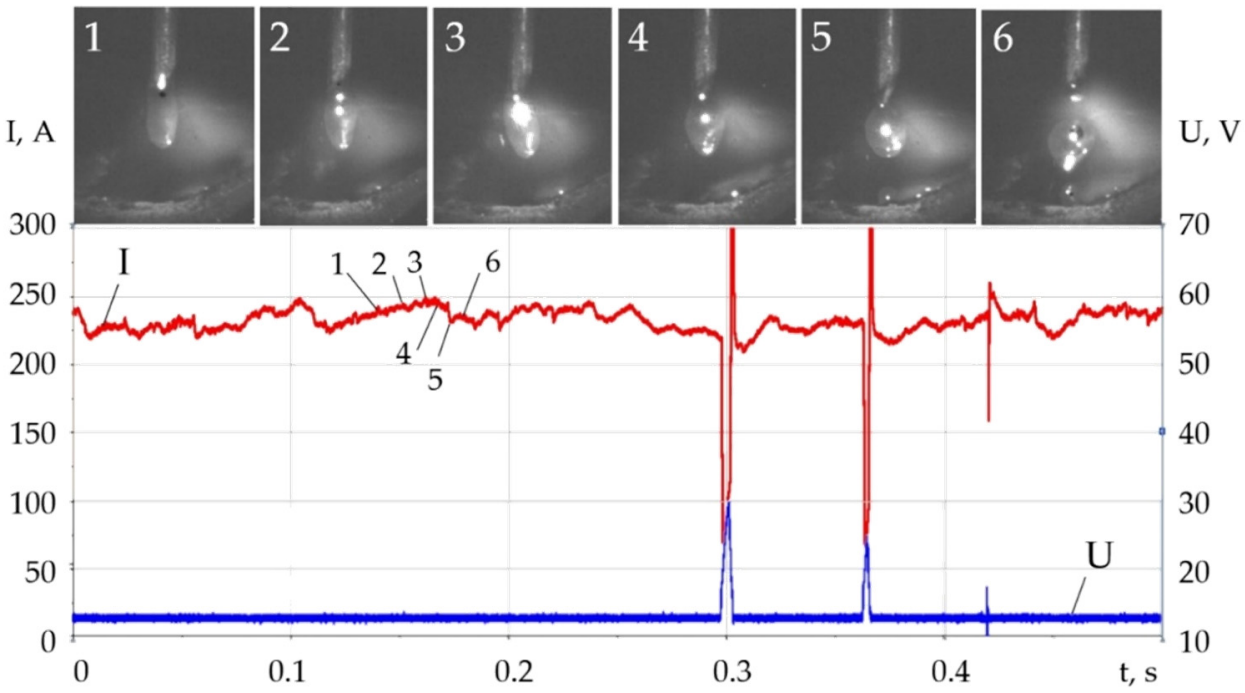

(b)

Figure 12. Change in the current and sequence of droplet transfer during melting of a 316L wire of $1.0 \mathrm{~mm}$ in argon: (a) uncoated wire; time between the frames is $1 \mathrm{~ms}$; (b) wire with a Ni-LaB 6 coating of $5 \mu \mathrm{m}$; time between the frames is $5 \mathrm{~ms} ; 1-6$ is a sequence of frames.

The application of gaseous sulfur fluoride $\mathrm{SF}_{6}$ has a significant effect on wire melting. When $1.6 \mathrm{wt} \% \mathrm{SF}_{6}$ was introduced into argon, the $316 \mathrm{~L}$ wire melted with the formation of droplets up to $1.6 \mathrm{~mm}$ in diameter without short circuits, as shown in Figure 13a. 


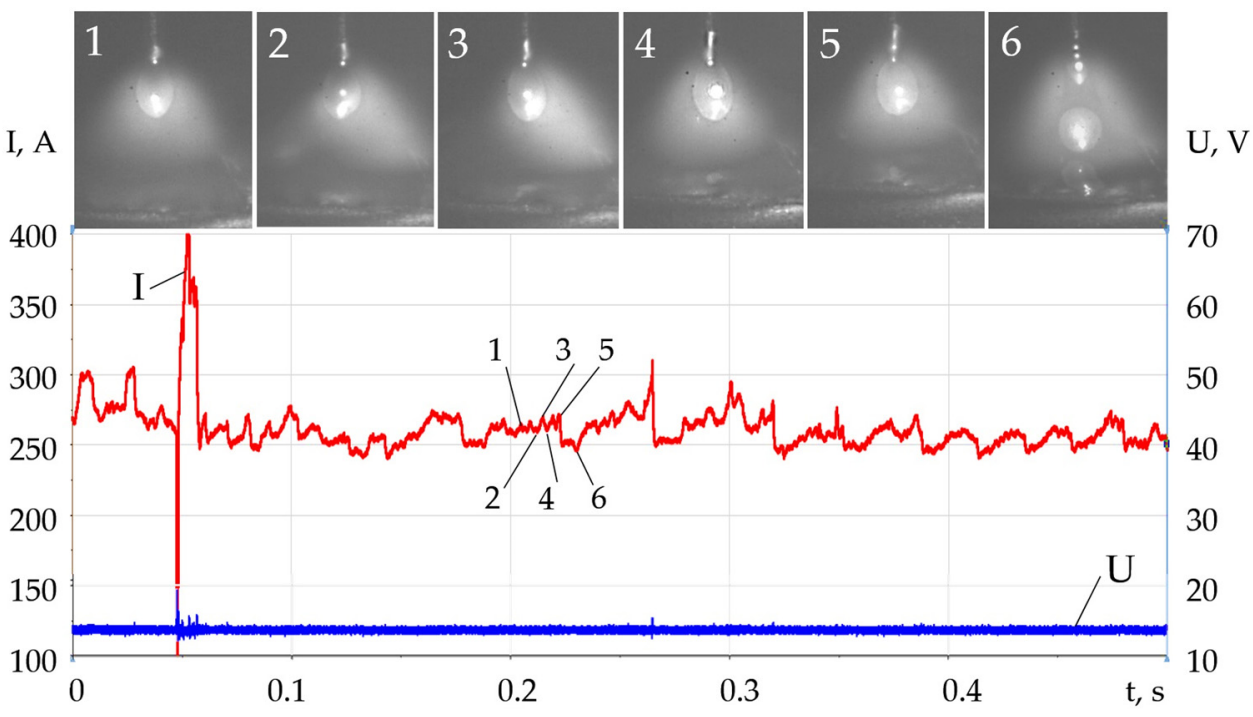

(a)

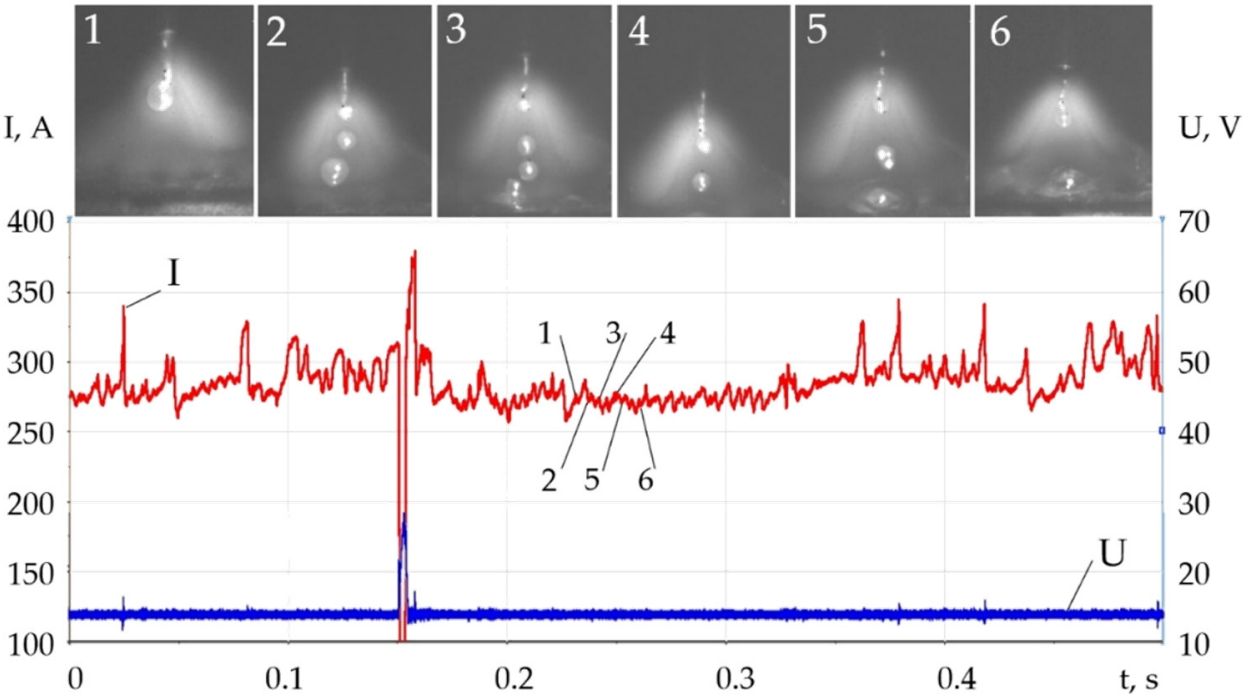

(b)

Figure 13. Change in the current and sequence of droplet transfer during melting of 316L wire of $1.0 \mathrm{~mm}$ in the mixture, wt.\%: (a) gas mixture of $98.4 \mathrm{Ar}+1.6 \mathrm{SF}_{6} ;(\mathbf{b})$ gas mixture of $96.8 \mathrm{Ar}+3.2 \mathrm{SF}_{6}$. Time between the frames is $5 \mathrm{~ms} ; 1-6$ is a sequence of frames.

The average arc length was $6 \mathrm{~mm}$ at the welding current of 239-285 A, the arc voltage of 13.2-14.2 V, and the power of 3.2-4 kW. With an increase in the $\mathrm{SF}_{6}$ content to $3.2 \mathrm{wt} . \%$, the droplet diameter decreased to 1-1.5 $\mathrm{mm}$. The average arc length was $6.2 \mathrm{~mm}$ at the welding current of $280-320 \mathrm{~A}$, arc voltage of $13.4-14.6 \mathrm{~V}$, power of $3.6-4.6 \mathrm{~kW}$, as shown in Figure 13b. An increase in the $\mathrm{SF}_{6}$ content to $6.4 \mathrm{wt} . \%$ caused an increase in the droplet diameter to $2-2.3 \mathrm{~mm}$. The average arc length was $6 \mathrm{~mm}$ at the welding current of 290-340 A, the arc voltage of 13.5-15 V, the power of 4-5 kW, as shown in Figure 14. 


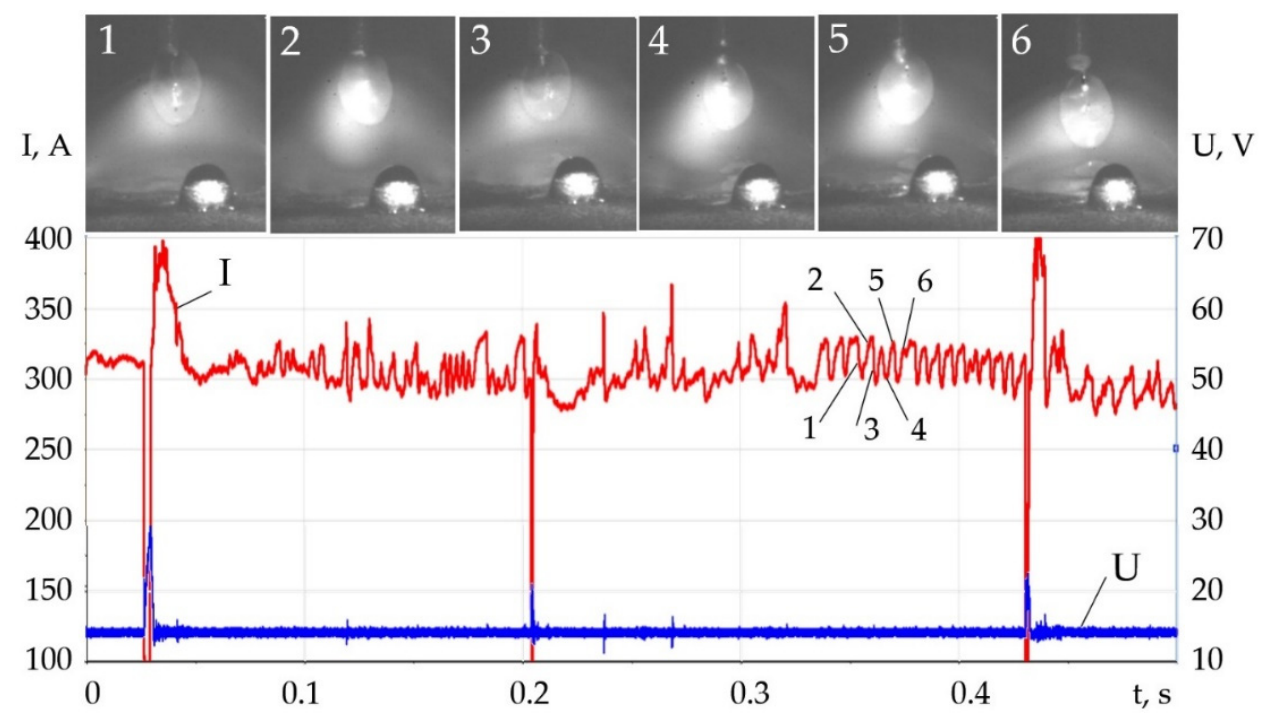

Figure 14. Change in the current and sequence of droplet transfer during melting of $316 \mathrm{~L}$ wire of $1.0 \mathrm{~mm}$ in the gas mixture, wt. $\%: 93.6 \mathrm{Ar}+6.4 \mathrm{SF}_{6}$. Time between the frames is $5 \mathrm{~ms} ; 1-6$ is a sequence of frames.

Thus, an increase in the $\mathrm{SF}_{6}$ fluoride content within 1.6-6.4, wt.\%, causes an increase in the current by $18-49 \%$, the arc voltage by $9-15 \%$, and the arc power by $23-66 \%$. Surfacing of the deposited beads showed that when 1.6-3.2 wt. $\% \mathrm{SF}_{6}$ is introduced into argon, the width of beads decreases by $4.8-9.1 \%$, and the penetration depth increases by $18-45.4 \%$. Since the parameters of the current source did not change, the changes in the current, voltage, power, weld width, and penetration depth can only be explained by the effect of $\mathrm{SF}_{6}$ on wire melting, balance of forces, thermophysical properties, and ionization of the arc plasma.

Melting of AlMg5Mn1Ti wire with a diameter of $1.6 \mathrm{~mm}$ in pure argon occurred with the formation of droplets with 2-3 mm diameter with spattering and microexplosions of droplets, as shown in Figure 15a.

At a wire feed rate of $6 \mathrm{~m} / \mathrm{min}$, the addition of $\mathrm{SF}_{6}$ at concentration of 1.6-6.4 wt.\% reduced the droplet diameter to $1.5-2 \mathrm{~mm}$, increased the average current by $4-13.8 \%$, and decreased the average voltage by $2.4-8.9 \%$. The droplet transfer frequency increased from $56 \mathrm{~Hz}$ to $78 \mathrm{~Hz}$, as shown in Figure 15b. When 1.6-3.2 wt.\% SF 6 was introduced into argon, the width of the deposited bead decreased by $17.2-28.6 \%$, and the depth of penetration increased by $11.7-52.9 \%$, depending on the wire feed rate in the range of $6-9 \mathrm{~m} / \mathrm{min}$. The reasons for the improvement in wire melting parameters with the application of $\mathrm{SF}_{6}$ are increase in enthalpy, thermal conductivity, heat capacity, and plasma ionization. 


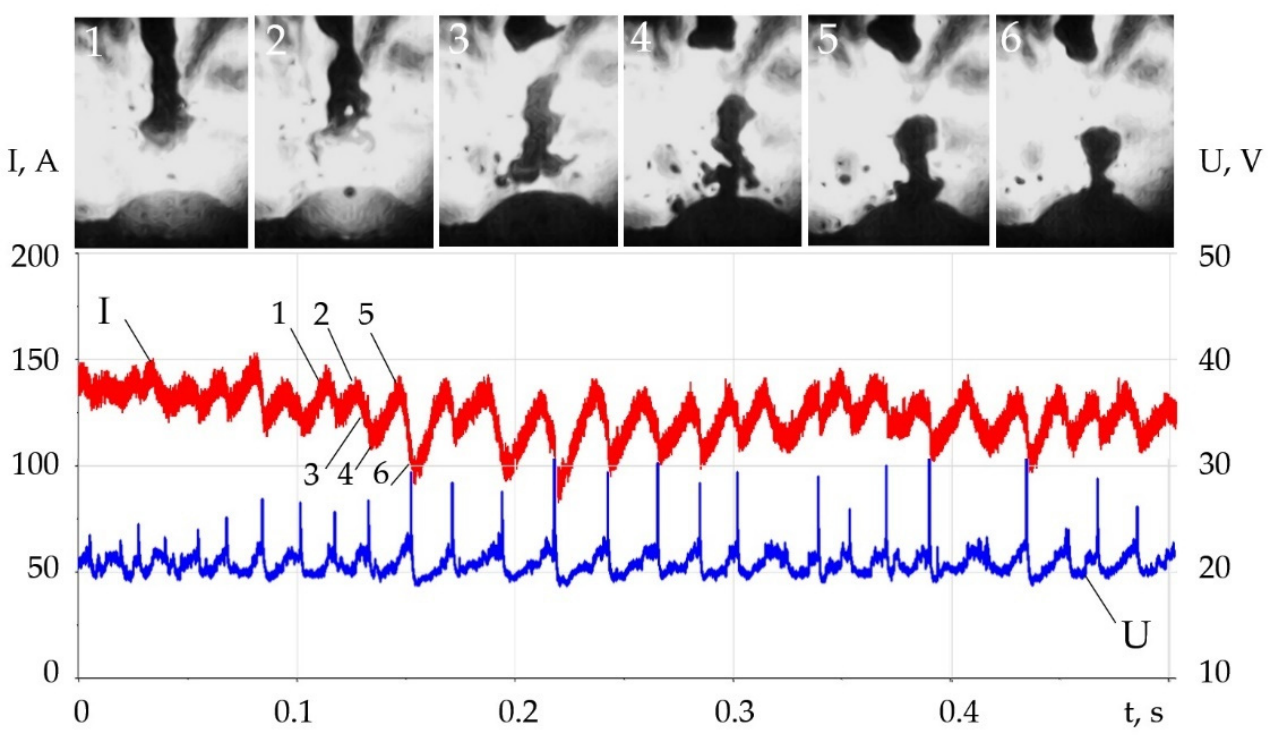

(a)

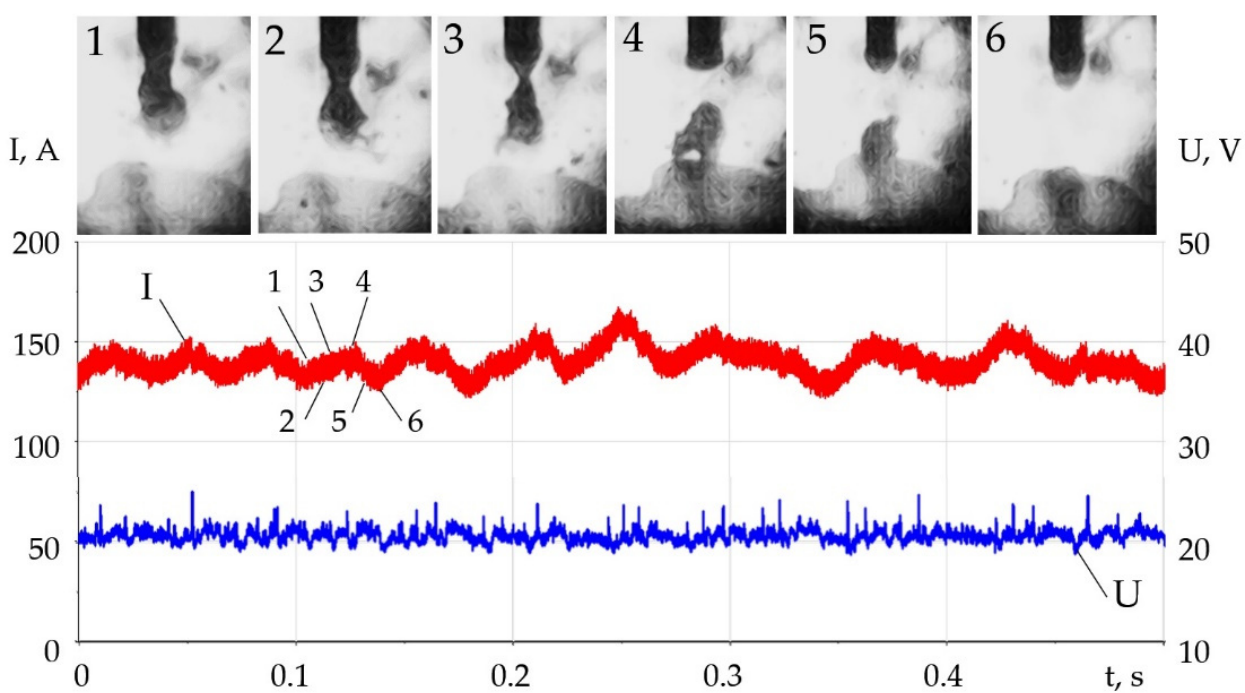

(b)

Figure 15. Change in the current and sequence of droplet transfer during melting AlMg5Mn1Ti wire of $1.6 \mathrm{~mm}$ : (a) pure argon; (b) gas mixture, wt.\%: $98.4 \mathrm{Ar}+1.6 \mathrm{SF}_{6}$. Time between the frames is $5 \mathrm{~ms}$; $1-6$ is a sequence of frames.

Changing the thermophysical properties of the arc and improving the melting of the wires with the application of $\mathrm{LaF}_{3}, \mathrm{LaB}_{6}$, and $\mathrm{SF}_{6}$ made it possible to obtain a technological effect for the formation of specimens in the robotic WAAM technology, as shown in Figures 16-19. 

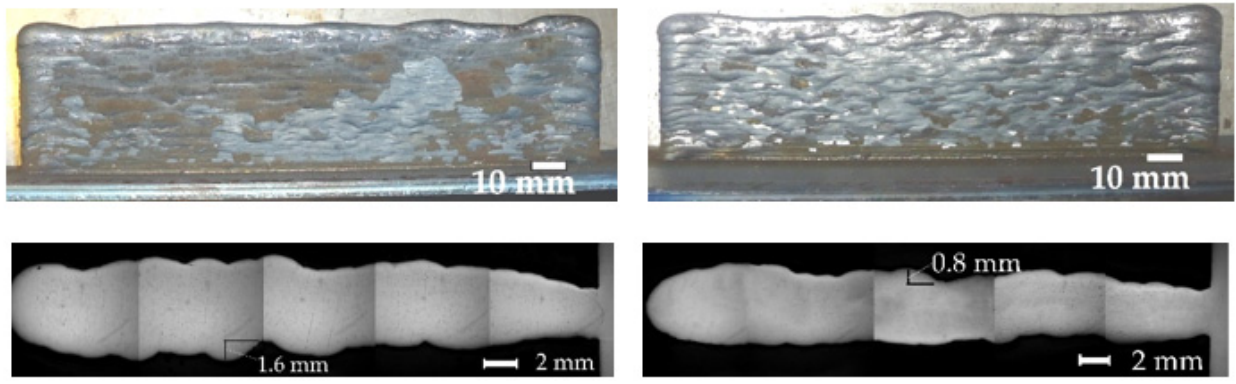

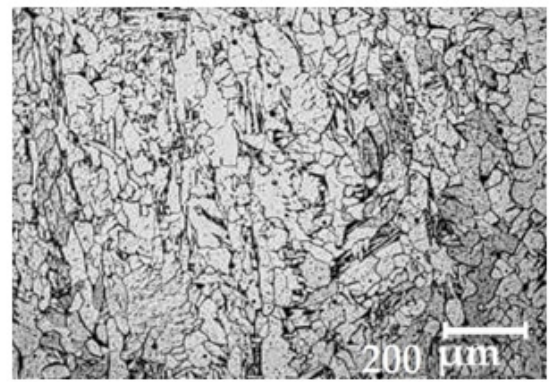

(a)

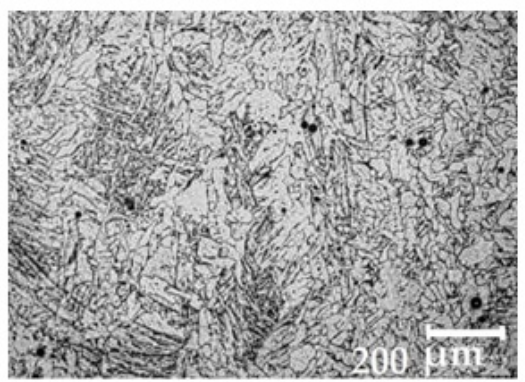

(b)

Figure 16. Formation, macrostructure and microstructure of a vertical specimen cross-section with G3Si1 wire of $1.2 \mathrm{~mm}$ : (a) uncoated wire, specimen thickness is $6 \mathrm{~mm}$, layer thickness is 2-2.2 $\mathrm{mm}$; (b) wire with $\mathrm{Ni}-\mathrm{LaF}_{3}$ composite coating, specimen thickness is $5 \mathrm{~mm}$, layer thickness is $1.5-2 \mathrm{~mm}$.
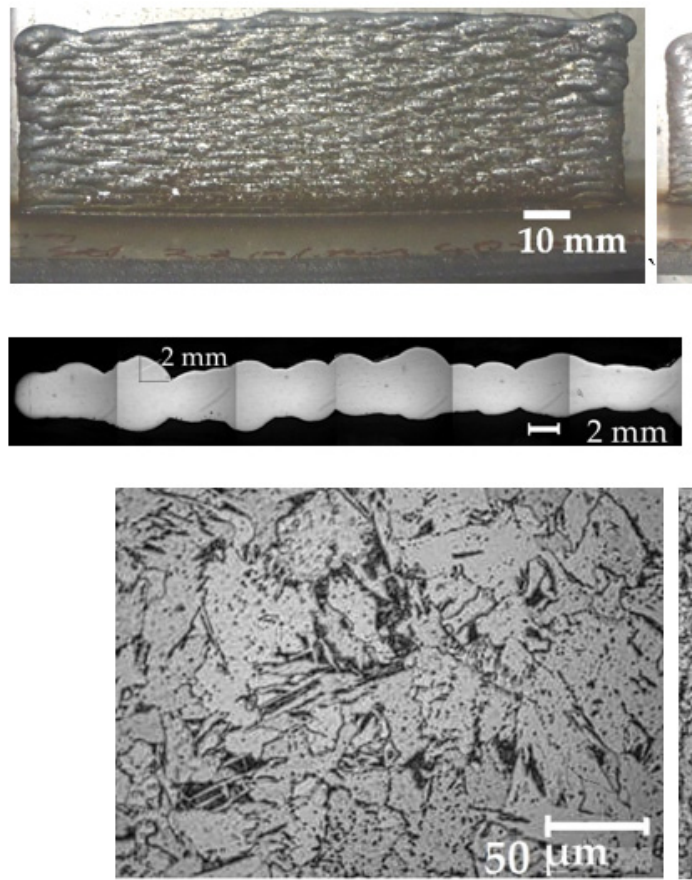

(a)
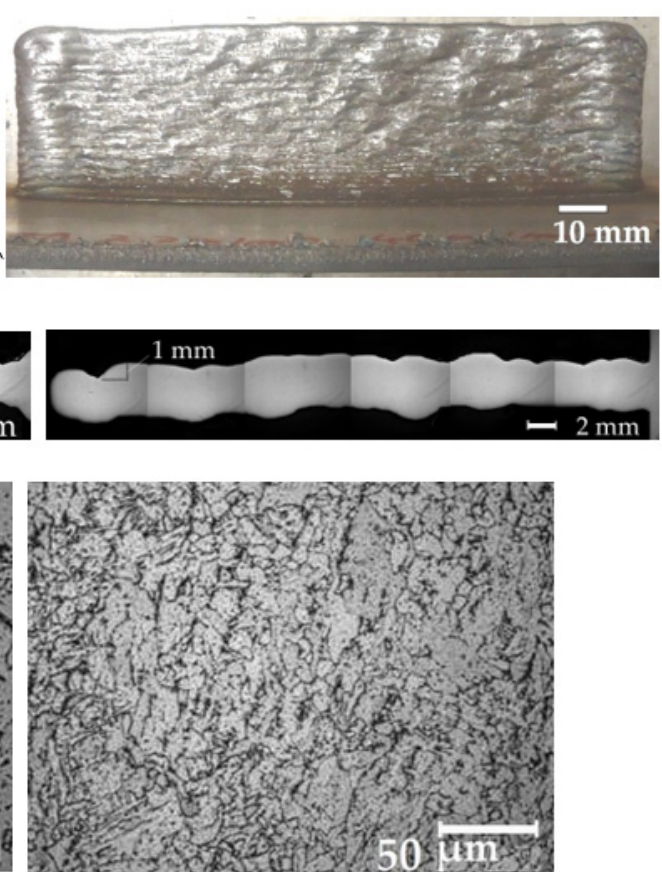

(b)

Figure 17. Formation, macrostructure and microstructure of a vertical specimen cross-section with 316L wire of $1 \mathrm{~mm}$ : (a) uncoated wire, specimen thickness is $4 \mathrm{~mm}$, layer thickness is $2-2.5 \mathrm{~mm}$; (b) wire with $\mathrm{Ni}^{-\mathrm{LaB}_{6}}$ composite coating, specimen thickness is $4 \mathrm{~mm}$, layer thickness is $1.5-2 \mathrm{~mm}$. 

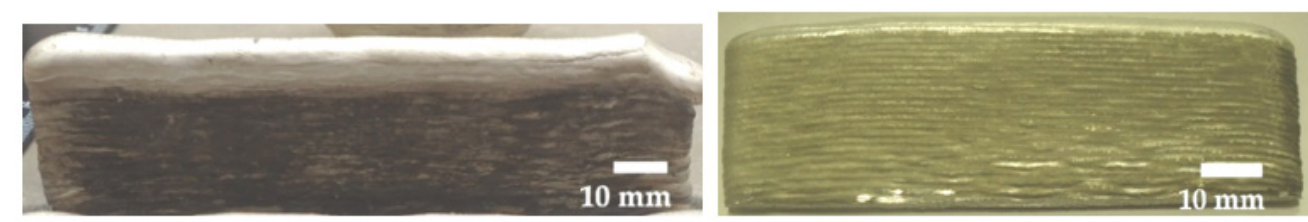

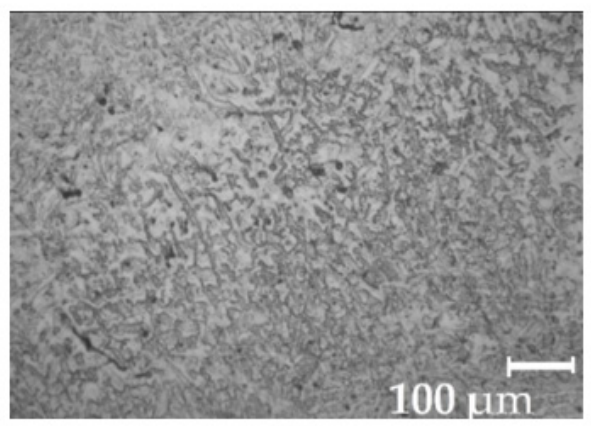

(a)

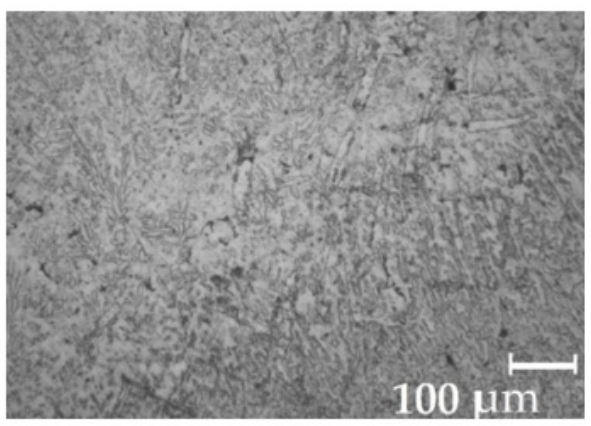

(b)

Figure 18. Formation and microstructure of a vertical specimen cross-section with AlMg5Mn1Ti wire of $1.6 \mathrm{~mm}$ : (a) pure argon, specimen thickness is $6.5 \mathrm{~mm}$, layer thickness is $2-2.5 \mathrm{~mm}$; (b) gas mixture with the addition of $1.6 \mathrm{wt} . \% \mathrm{SF}_{6}$ into argon, specimen thickness is $4 \mathrm{~mm}$, layer thickness is $0.8-1 \mathrm{~mm}$.

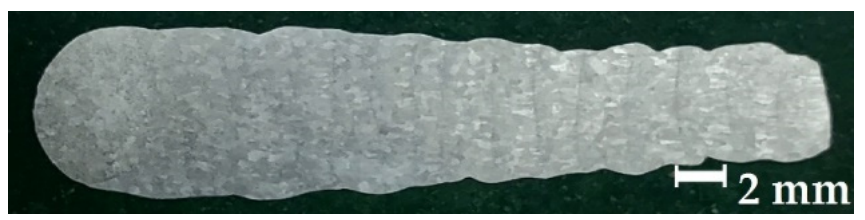

(a)

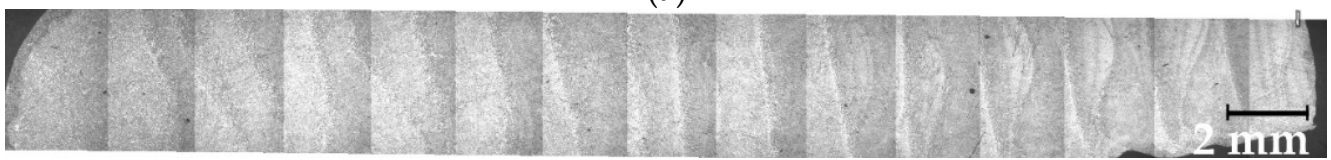

(b)

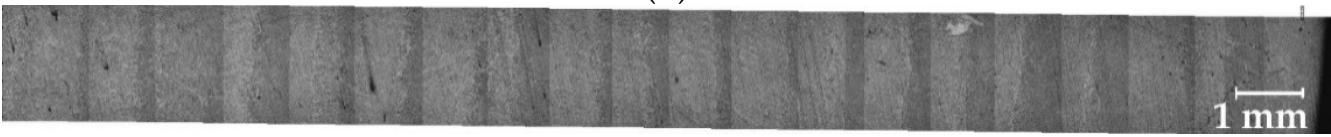

(c)

Figure 19. Optical macrostructure of the specimen with AlMg5Mn1Ti wire in WAAM: (a) crosssection of the specimen during deposition in pure argon; (b) cross-section of the specimen during deposition in the mixture of $\mathrm{Ar}+1.6 \mathrm{wt} . \% \mathrm{SF}_{6}$; and (c) part of the longitudinal section of the specimen during deposition in the mixture of $\mathrm{Ar}+1.6 \mathrm{wt} . \% \mathrm{SF}_{6}$.

A significant improvement was achieved during the formation of a vertical multilayer specimen using the G3Si1 wire with $\mathrm{Ni}-\mathrm{LaF}_{3}$ composite coating, the $316 \mathrm{~L}$ wire with a $\mathrm{Ni}-\mathrm{LaB}_{6}$ composite coating, as well as the AlMg5Mn1Ti wire with $1.6 \mathrm{wt} . \% \mathrm{SF}_{6}$ added to argon. The reason for the increase in the accuracy of geometric dimensions ( 2 times) was the improvement in the formation of the deposited metal due to the improvement in the stability of the arc and the melting of the wires. Higher accuracy made it possible to eliminate defects and errors in the layer-by-layer formation of a vertical specimen, to reduce the number of short circuits, and to reduce the wall specimen thickness by $20-50 \%$. The addition of fluorides helped to clean the surface of the specimen from slag and oxides.

A noticeable effect is also the refinement of grains in the microstructure of the deposited metal with G3Si1-Ni-LaF 3 and 316L-Ni-LaB 6 wires, which may be due to the modifying effect of La on the limited growth of crystallites and the formation of additional crystallization nuclei in the weld pool. The refinement of the microstructure of the 
AlMg5Mn1Ti wire deposited metal with the addition of $\mathrm{SF}_{6}$ is caused by the limitation of crystallite growth due to the adsorption of sulfur on the growing crystal grains.

Thus, studies have shown a positive effect of fluorides $\mathrm{LaF}_{3}, \mathrm{SF}_{6}$, and boride $\mathrm{LaB}_{6}$ on the formation of vertical specimens and the microstructure of the deposited metal. Additional tests have shown that a positive effect from the addition of $\mathrm{SF}_{6}$ is observed in WAAM of complex-shaped products made of AlMg5Mn1Ti alloy and CuCr0.7 alloy, as shown in Figures 20 and 21.

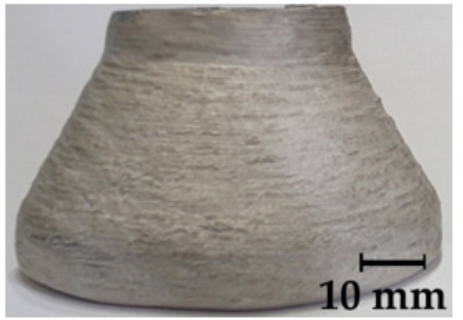

(a)
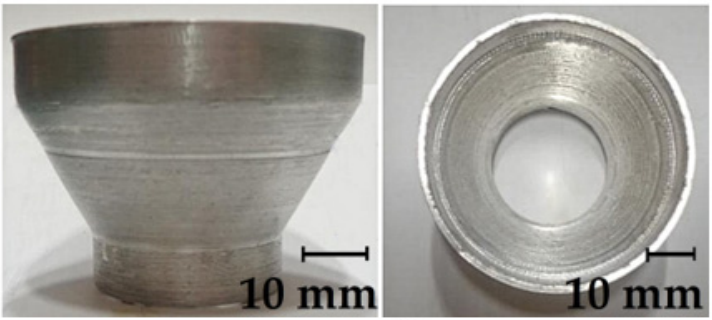

(b)

Figure 20. Nozzle with AlMg5Mn1Ti wire in WAAM: before (a) and after (b) machining. Nozzle diameter is $35-60 \mathrm{~mm}$, specimen thickness before machining is $5 \mathrm{~mm}$. WAAM with the addition of $1.6 \mathrm{wt} . \% \mathrm{SF}_{6}$ into argon.

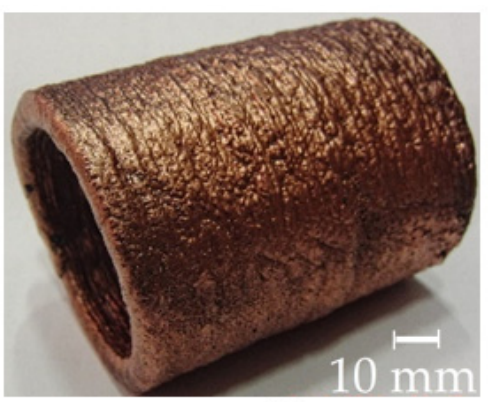

(a)

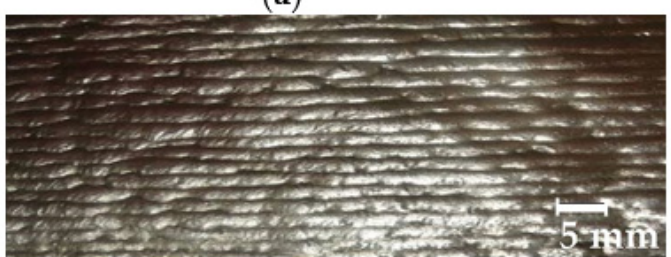

(c)

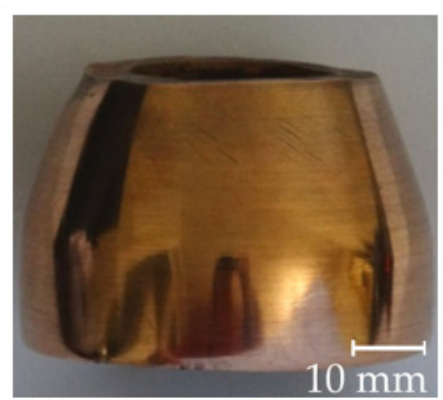

(b)
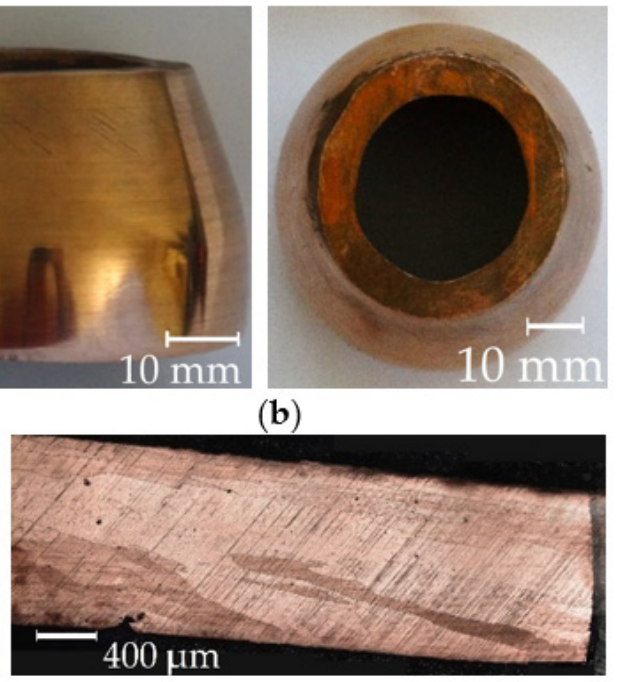

(d)

Figure 21. Bronze nozzle with CuCr0.7 wire in WAAM: before (a) and after (b) machining; the macrostructure of the surface (c) and the microstructure of the cross-section of the wall specimen (d). The diameter of the nozzle is $60 \mathrm{~mm}$, the thickness of the specimen before machining is $5 \mathrm{~mm}$. WAAM with the addition of $1.6 \mathrm{wt} . \% \mathrm{SF}_{6}$ into argon.

The addition of $\mathrm{SF}_{6}$ to WAAM of complex-shaped products with $\mathrm{CuCr} 0.7$ wire brings a positive result: it increases the accuracy of the product geometry and reduces the layer thickness to $1-1.3 \mathrm{~mm}$ at a high density of the deposited metal. The results obtained allow us to predict the positive effect of using fluorides and borides of rare-earth metals, as well as fluoride sulfur $\mathrm{SF}_{6}$ for WAAM of products from various alloys, including the filler wires from magnesium, titanium, nickel, and intermetallic alloys.

\section{Conclusions}

1. For WAAM developed composite wires with a Ni-LaF $3, \mathrm{Ni}^{-\mathrm{LaB}_{6}}$ coating, the addition of $\mathrm{LaF}_{3}, \mathrm{LaB}_{6}$, and $\mathrm{SF}_{6}$ forms a molecular layer at the arc boundary at a temperature of $1000-6000 \mathrm{~K}$, in which endothermic dissociation and ionization reactions take place. Under the influence of concentration and ambipolar diffusion, atoms, ions, and 
electrons are distributed in the longitudinal and transverse directions over the volume of the plasma, depending on the ionization energy and the atomic weight of the elements. Saturation of plasma with products of dissociation and ionization increases the specific heat, thermal conductivity, enthalpy, degree of ionization, and decreases the dynamic viscosity of the plasma. The change of the thermophysical properties of the plasma and the increase in the electron concentration led to an increase in the transfer of heat from the arc plasma to the surface of the wire.

2. When $\mathrm{LaF}_{3}$ is added at $4000-6000 \mathrm{~K}$, the specific heat of the plasma increases from 0.5 to $3.3 \mathrm{~J} /(\mathrm{kg} \times \mathrm{K})$, the thermal conductivity increases from 0.1 to $0.18 \mathrm{~W} /(\mathrm{m} \times \mathrm{K})$, and the enthalpy grows from 2000 to $4000 \mathrm{~J} / \mathrm{kg}$, the electron concentration increases from 1 to $2 \mathrm{~mol} / \mathrm{kg}$ at $10,000 \mathrm{~K}$. When $\mathrm{LaB}_{6}$ is added at $8000-10,000 \mathrm{~K}$, the specific heat increases from 0.6 to $2.2 \mathrm{~J} /(\mathrm{kg} \times \mathrm{K})$, thermal conductivity grows from 0.16 to $0.22 \mathrm{~W} /(\mathrm{m} \times \mathrm{K})$, enthalpy increases from 6000 to $13000 \mathrm{~J} / \mathrm{kg}$, electron concentration grows from 1 to $4 \mathrm{~mol} / \mathrm{kg}$. When SF6 is added at 4000-6000 K, the specific heat increases from 0.5 to $2.5 \mathrm{~J} /(\mathrm{kg} \times \mathrm{K})$, the thermal conductivity increases from 0.1 to $0.3 \mathrm{~W} /(\mathrm{m} \times \mathrm{K})$, the enthalpy grows from 6000 to $9000 \mathrm{~J} / \mathrm{kg}$ at $10,000 \mathrm{~K}$, the electron concentration decreases from 0.06 to $0.02 \mathrm{~mol} / \mathrm{kg}$.

3. Changes in the thermophysical properties of plasma with the addition of $\mathrm{LaF}_{3}, \mathrm{LaB}_{6}$, and $\mathrm{SF}_{6}$ improved ionization, increased heat transfer from the plasma to the anode and surface adsorption of $\mathrm{La}, \mathrm{B}$, and $\mathrm{S}$ are the reasons for the change in the balance of forces acting during the droplet transfer. The greatest effect is observed in the growth of the Lorentz electromagnetic force, since there is an increase in the concentration of electrons. Experimentally, this is confirmed by an increase in the welding current up to $7-21 \%$. Another effect is a decrease in the surface tension force with an increase in the droplet temperature and surface adsorption of $\mathrm{La}, \mathrm{B}, \mathrm{S}$.

4. The change in the balance of forces during melting of the wire, the increase in the Lorentz electromagnetic force, and the decrease in the surface tension force led to the decrease in the diameter of the droplets and improved droplet transfer. The balance of forces should take into account the normal reactive force and the tangential force of the Marangoni effect, which requires a further study. With the addition of $\mathrm{LaF}_{3}$ during melting of the G3Si1 wire, the droplet diameter decreased from 2.5 to $2 \mathrm{~mm}$, the frequency of short circuits decreased from 40 to $4 \mathrm{~Hz}$. The addition of $\mathrm{LaB}_{6}$ and $3.2 \mathrm{wt} . \% \mathrm{SF}_{6}$ when melting the $316 \mathrm{~L}$ wire reduced the droplet diameter from 2.6 to 1-1.2 mm without short circuits. When melting the AlMg5Mn1Ti wire, the addition of $\mathrm{SF}_{6}$ to $6.4 \mathrm{wt} . \%$ reduced the droplet diameter from 3.0 to $1.5 \mathrm{~mm}$.

5. The change of the thermophysical properties of plasma and droplet transfer during melting of wires with the addition of $\mathrm{LaF}_{3}, \mathrm{LaB}_{6}$, and $\mathrm{SF}_{6}$ made the WAAM technologically effective for manufacturing products of complex shape using G3Si1, 316L, AlMg5Mn1Ti, and $\mathrm{CuCr} 0.7$ wires. This effect increased the accuracy of the geometry of products by two times, reduced the thickness of the deposited metal layer by 1.25-2 times, and refined the microstructure of the deposited metal, which indicates that the goal of the study has been achieved.

Author Contributions: Conceptualization, S.G.P.; methodology, S.G.P.; software, validation, S.G.P.; formal analysis, P.M.; investigation, S.G.P.; resources, P.M.; data curation, P.M.; writing-original draft preparation, S.G.P.; writing-review and editing, P.M.; visualization, S.G.P.; supervision, S.G.P.; project administration, S.G.P. All authors have read and agreed to the published version of the manuscript.

Funding: This research was supported by the project "Energy-efficient systems based on renewable energy for Arctic conditions" (EFREA), KS1054, South-East Finland-Russia CBC Program 2014-2020 and by the German Academic Exchange Service, Program 2018 (57381327).

Institutional Review Board Statement: Not applicable.

Informed Consent Statement: Not applicable. 
Data Availability Statement: Data sharing is not applicable.

Conflicts of Interest: The authors declare no conflict of interest.

\section{References}

1. Rodrigues, T.A.; Duarte, V.; Miranda, R.M.; Santos, T.G.; Oliveira, J.P. Current Status and Perspectives on Wire and Arc Additive Manufacturing (WAAM). Materials 2019, 12, 1121. [CrossRef] [PubMed]

2. Jin, W.; Zhang, C.; Jin, S.; Tian, Y.; Wellmann, D.; Liu, W. Wire Arc Additive Manufacturing of Stainless Steels: A Review. Appl. Sci. 2020, 10, 1563. [CrossRef]

3. Wu, B.; Pan, Z.; Ding, D.; Cuiuri, D.; Li, H.; Xu, J.; Norrish, J. A Review of the Wire Arc Additive Manufacturing of Metals: Properties, Defects and Quality Improvement. J. Manuf. Process. 2018, 35, 127-139. [CrossRef]

4. Elmer, J.W.; Vaja, J.; Carpenter, J.S.; Coughlin, D.R.; Dvornak, M.J.; Hochanadel, P.; Gurung, P.; Johnson, A.; Gibbs, G. Wire-Based Additive Manufacturing of Stainless Steel Components. Weld. J. 2020, 99, 8-24. [CrossRef]

5. Posch, G.; Chladi, K.; Chladil, H. Material Properties of CMT-Metal Additive Manufactured Duplex Stainless Steel Blade-Like Geometries. Weld. World 2017, 61, 873-882. [CrossRef]

6. Huynh, L.; Rotella, J.; Sangid, M.D. Fatigue Behavior of IN718 Microtrusses Produced via Additive Manufacturing. Mater. Des. 2016, 105, 278-289. [CrossRef]

7. Zhai, Y.; Galarraga, H.; Lados, D.A. Microstructure, Static Properties, and Fatigue Crack Growth Mechanisms in Ti-6Al-4V Fabricated by Additive Manufacturing: LENS and EBM. Eng. Fail. Anal. 2016, 69, 3-14. [CrossRef]

8. Baby, J.; Amirthalingam, M. Microstructural Development During Wire Arc Additive Manufacturing of Copper-Based Components. Weld. World 2020, 64, 395-405. [CrossRef]

9. Shakil, S.I.; Dharmendra, C.; Amirkhiz, B.S.; Verma, D.; Mohammadi, M.; Haghshenas, M. Micromechanical Characterization of Wire-Arc Additive Manufactured and Cast Nickel Aluminum Bronze: Ambient and Intermediate Temperatures. Mater. Sci. Eng. A 2020, 792, 139773. [CrossRef]

10. Gierth, M.; Henckell, P.; Ali, Y.; Scholl, J.; Bergmann, J.P. Wire Arc Additive Manufacturing (WAAM) of Aluminum Alloy AlMg5Mn with Energy-Reduced Gas Metal Arc Welding (GMAW). Materials 2020, 13, 2671. [CrossRef]

11. Köhler, M.; Fiebig, S.; Hensel, J.; Dilger, K. Wire and Arc Additive Manufacturing of Aluminum Components. Metals 2019, 9, 608. [CrossRef]

12. Silva, C.M.A.; Braganca, I.M.F.; Cabrita, A.; Quintino, L.; Martins, P.A.F. Formability of a Wire Arc Deposited Aluminium Alloy. J. Braz. Soc. Mech. Sci. Eng. 2017, 39, 4059-4068. [CrossRef]

13. Ge, J.; Ma, T.; Chen, Y.; Jin, T.; Fu, H.; Xiao, R.; Lei, Y.; Lin, J. Wire-Arc Additive Manufacturing H13 Part: 3D Pore Distribution, Microstructural Evolution, and Mechanical Performances. J. Alloys Compd. 2019, 783, 145-155. [CrossRef]

14. Seow, C.E.; Coules, H.E.; Wu, G.; Khan, R.H.U.; Xu, X.; Williams, S. Wire + Arc Additively Manufactured Inconel 718: Effect of Post-Deposition Heat Treatments on Microstructure and Tensile Properties. Mater. Des. 2019, 183, 108157. [CrossRef]

15. Cong, B.; Ding, L.; Williams, S. Effect of Arc Mode in Cold Metal Transfer Process on Porosity of Additively Manufactured Al-6.3\%Cu Alloy. Int. J. Adv. Manuf. Technol. 2015, 76, 1593-1606. [CrossRef]

16. Haden, C.V.; Zeng, G.; Carter, F.M., III; Ruhl, C.; Krick, B.A.; Harlow, D.G. Wire and Arc Additive Manufactured Steel: Tensile and Wear Properties. Addit. Manuf. 2017, 16, 115-123. [CrossRef]

17. Stützer, J.; Totzauer, T.; Wittig, B.; Zinke, M.; Jüttner, S. GMAW Cold Wire Technology for Adjusting the Ferrite-Austenite Ratio of Wire and Arc Additive Manufactured Duplex Stainless Steel Components. Metals 2019, 9, 564. [CrossRef]

18. Müller, J.; Grabowski, M.; Müller, C.; Hensel, J.; Unglaub, J.; Thiele, K.; Kloft, H.; Dilger, K. Design and Parameter Identification of Wire and Arc Additively Manufactured (WAAM) Steel Bars for Use in Construction. Metals 2019, 9, 725. [CrossRef]

19. Ding, J.; Colegrove, P.; Mehnen, J.; Ganguly, S.; Almeida, P.S.; Wang, F.; Williams, S. Thermo-Mechanical Analysis of Wire and Arc Additive Layer Manufacturing Process on Large Multi-Layer Parts. Comput. Mater. Sci. 2011, 50, 3315-3322. [CrossRef]

20. Dahat, S.; Hurtig, K.; Andersson, J.; Scotti, A. A Methodology to Parameterize Wire + Arc Additive Manufacturing: A Case Study for Wall Quality Analysis. J. Manuf. Mater. Process. 2020, 4, 14. [CrossRef]

21. Lee, S.H. CMT-Based Wire Arc Additive Manufacturing Using 316L Stainless Steel: Effect of Heat Accumulation on the MultiLayer Deposits. Metals 2020, 10, 278. [CrossRef]

22. Rodrigues, T.A.; Duarte, V.; Avila, J.A.; Santos, T.G.; Miranda, R.M.; Oliveira, J.P. Wire and Arc Additive Manufacturing of HSLA Steel: Effect of Thermal Cycles on Microstructure and Mechanical Properties. Addit. Manuf. 2019, 27, 440-450. [CrossRef]

23. Hosseini, V.A.; Högström, M.; Hurtig, K.; Bermejo, M.A.V.; Stridh, L.-E.; Karlsson, L. Wire-Arc Additive Manufacturing of a Duplex Stainless Steel: Thermal Cycle Analysis and Microstructure Characterization. Weld. World 2019, 63, 975-987. [CrossRef]

24. Xia, C.; Pan, Z.; Polden, J.; Li, H.; Xu, Y.; Chen, S.; Zhang, Y. A Review on Wire Arc Additive Manufacturing: Monitoring, Control and a Framework of Automated System. J. Manuf. Syst. 2020, 57, 31-45. [CrossRef]

25. Mirapeix, J.; Cobo, A.; Fuentes, J.; Davila, M.; Etayo, J.M.; Lopez-Higuera, J.-M. Use of the Plasma Spectrum RMS Signal for Arc-Welding Diagnostics. Sensors 2009, 9, 5263-5276. [CrossRef] [PubMed]

26. Panda, B.; Shankhwar, K.; Garg, A.; Savalani, M.M. Evaluation of Genetic Programming-Based Models for Simulating Bead Dimensions in Wire and Arc Additive Manufacturing. J. Intell. Manuf. 2019, 30, 809-820. [CrossRef]

27. Parshin, S.G. Metallurgy of Welding; Politech-Press: Saint-Petersburg, Russia, 2020; pp. 71-144. (In Russian) 
28. Sames, W.J.; List, F.A.; Pannala, S.; Dehoff, R.R.; Babu, S.S. The Metallurgy and Processing Science of Metal Additive Manufacturing. Int. Mater. Rev. 2016, 61, 315-360. [CrossRef]

29. Wittig, B.; Zinke, M.; Jüttner, S. Influence of Arc Energy and Filler Metal Composition on the Microstructure in Wire Arc Additive Manufacturing of Duplex Stainless Steels. Weld. World 2021, 65, 47-56. [CrossRef]

30. Asala, G.; Khan, A.K.; Andersson, J.; Ojo, O.A. Microstructural Analyses of ATI 718Plus Produced by Wire-Arc Additive Manufacturing Process. Metall. Mater. Trans. A 2017, 48, 4211-4228. [CrossRef]

31. Hertel, M.; Trautmann, M.; Jäckel, S.; Füssel, U. The Role of Metal Vapour in Gas Metal Arc Welding and Methods of Combined Experimental and Numerical Process Analysis. Plasma Chem. Plasma Process. 2017, 37, 48-54. [CrossRef]

32. Wagner, R.; Siewert, E.; Schein, J.; Hussary, N.; Jaeckel, S. Shielding Gas Influence on Emissions in Arc Welding. Weld. World 2018, 62, 647-652. [CrossRef]

33. Sumi, H.; Kataoka, T.; Kitani, Y. Application of Narrow Gap Welding Process with "J-STARTM Welding" to Shipbuilding and Construction. JFE Tech. Rep. 2015, 20, 112-117.

34. Weglowski, M.S. Modeling and Analysis of the Arc Light Spectrum in GMAW. Weld. J. 2008, 87, $212-218$.

35. Wang, C.; Wu, Y.; Chen, Z.; Yang, F.; Feng, Y.; Rong, M.; Zhang, H.; Chunlin, W.; Yi, W.; Zhexin, C.; et al. Thermodynamic and Transport Properties of Real Air Plasma in Wide Range of Temperature and Pressure. Plasma Sci. Technol. 2016, 18, 732-739. [CrossRef]

36. Kataoka, T.; Ikeda, R.; Ono, M.; Yasuda, K.; Hirata, Y. Effect of REM Addition of Wire on $\mathrm{CO}_{2}$ Gas Shielded Arc Phenomenon. Weld. Int. 2009, 23, 517-522. [CrossRef]

37. Parshin, S.G.; Karkhin, V.A.; Mayr, P.; Maystro, A.S. The Effect of Electrochemical Composite Coatings with $\mathrm{LaF}_{3}-\mathrm{LaB}_{6} \mathrm{Particles}$ in Nickel-Copper Matrix on the Metallurgical Processes in Arc Welding of Low Alloy Ferrite-Pearlite Steels. Materials 2021, 14, 1509. [CrossRef] [PubMed]

38. Parshin, S.G. Metallurgical Effect of Rare-Earth Lanthanum Fluoride and Boride in the Composite Coating of Wires in the Arc Welding of Bainitic-Martensitic and Austenitic Steel. Metals 2020, 10, 1334. [CrossRef]

39. Parshin, S.G.; Parshin, S.S.; Buerckner, H.; Semmler, W.; Kush, M.; Reinhardt, S.; Kuhn, S. Intensification of Melting of Wires in MIG/MAG Welding of Steels and Aluminium Alloys. Weld. Int. 2011, 25, 47-51. [CrossRef]

40. Parshin, S.G. Using Ultrafine Particles of Activating Fluxes for Increasing the Productivity of MIG/MAG Welding of Steels. Weld. Int. 2012, 26, 800-804. [CrossRef]

41. Parshin, S.G. Increasing the Productivity of MIG Welding Aluminium Alloys by Adding Ultrafine Particles of Activating Fluxes. Weld. Int. 2013, 27, 735-739. [CrossRef]

42. Parshin, S.G. MAG Welding with Nanostructured Electrode Materials with Halide-Containing Coatings. Weld. Int. 2013, 27, 825-829. [CrossRef]

43. Parshin, S.G. Effect of Gaseous Sulphur Hexafluoride SF6 on the Process of MIG Welding of AlMg4.5Mn0.7 Aluminium alloy. Weld. Int. 2016, 30, 1-5. [CrossRef]

44. Parshin, S.G. MIG Welding of S235JR Steel with the Addition of Gaseous Sulphur Hexafluoride SF6 to Argon. Weld. Int. 2017, 31, 863-867. [CrossRef]

45. Kim, Y.S.; Eager, T.W. Analysis of Metal Transfer in Gas Metal Arc Welding. Weld. J. 1993, 72, 269-s.

46. Finkelnburg, W.; Maecker, H. Elektrische Bögen und thermisches Plasma. In Encyclopedia of Physics; Springer: Berlin/Heidelberg, Germany, 1956; Volume 22, pp. 254-444. (In Germany)

47. Egry, I.; Ricci, E.; Novakovic, R.; Ozawa, S. Surface Tension of Liquid Metals and Alloys-Recent Developments. Adv. Colloid Interface Sci. 2010, 159, 198-212. [CrossRef]

48. Sahoo, P.; Debroy, T.; McNallan, M.J. Surface Tension of Binary Metal—Surface Active Solute Systems under Conditions Relevant to Welding Metallurgy. Met. Mater. Trans. B 1988, 19, 483-491. [CrossRef]

49. Keene, B.J. Review of Data for the Surface Tension of Iron and its Binary Alloys. Int. Mater. Rev. 1988, 33, 1-37. [CrossRef]

50. Kasama, A.; McLean, A.; Miller, W.A.; Morita, Z.; Ward, M.J. Surface Tension of Liquid Iron and Iron-Oxygen Alloys. Can. Metall. Q. 1983, 22, 9-17. [CrossRef]

51. Korobeinikov, I.; Chebykin, D.; Seetharaman, S.; Volkova, O. Effect of Boron Micro-alloying on the Surface Tension of Liquid Iron and Steel Alloys. Int. J. Thermophys. 2020, 41, 1-14. [CrossRef]

52. Park, H.; Trautmann, M.; Tanaka, K.; Tanaka, V.; Murphy, A.B. A Computational Model of Gas Tungsten Arc Welding of Stainless Steel: The Importance of Considering the Different Metal Vapours Simultaneously. J. Phys. D Appl. Phys. 2018, 51, 395202. [CrossRef]

53. Matsushita, T.; Belov, I.; Siafakas, D.; Jarfors, A.E.W.; Watanabe, M. Interfacial Phenomena between Molten Iron and Molten Slag-Effect of Nitrogen on the Marangoni Convection. J. Mater. Sci. 2021, 56, 7811-7822. [CrossRef]

54. Waszink, J.Y.; Heuvel, G.L.P.M. Heat Generation and Heat Flow in the Filler Metal in GMA Welding. Weld. J. 1982, 8, $269-282$.

55. Karkhin, V.A. Thermal Processes in Welding; Springer: Singapore, 2019; pp. 381-390.

56. Granovsky, V.L. Electrical Current in Gas. Stationary Current; Nauka: Moscow, Russia, 1971; pp. 117-127. (In Russian)

57. Khrabry, A.; Kaganovich, I.D.; Nemchinsky, V.; Khodak, A. Investigation of the Short Argon Arc with Hot Anode. II. Analytical Model. Phys. Plasmas 2018, 25, 013522. [CrossRef]

58. Boulos, M.I.; Fauchais, P.L.; Pfender, E. Thermodynamic Properties of Plasmas. In Handbook of Thermal Plasmas; Springer: Cham, Switzerland, 2020; pp. 1-46. 
59. Maher, I.; Boulos, M.I.; Pierre, L.; Pfender, E. Plasma Radiation Transport. In Handbook of Thermal Plasmas; Springer: Cham, Switzerland, 2020; pp. 1-74.

60. Murphy, A.B.; Tanaka, M.; Yamamoto, K.; Tashiro, S.; Sato, T.; Lowke, J.J. Modelling of Thermal Plasmas for Arc Welding: The Role of the Shielding Gas Properties and of Metal Vapour. J. Phys. D Appl. Phys. 2009, 42, 194006. [CrossRef] 